OPEN ACCESS

Edited by:

Natalia V. Kirienko,

Rice University, United States

Reviewed by:

Wim J. Quax,

University of Groningen, Netherlands

Zaixiang Lou,

Jiangnan University, China

*Correspondence:

Mikael Elias

mhelias@umn.edu

David Daudé

david.daude@gene-greentk.com

Éric Chabrière

eric.chabriere@univ-amu.fr

Specialty section:

This article was submitted to Antimicrobials, Resistance

and Chemotherapy,

a section of the journal

Frontiers in Microbiology

Received: 07 January 2020

Accepted: 30 March 2020

Published: 24 April 2020

Citation:

Rémy B, Plener $L$,

Decloquement P, Armstrong N,

Elias M, Daudé $D$ and Chabrière É

(2020) Lactonase Specificity Is Key

to Quorum Quenching

in Pseudomonas aeruginosa.

Front. Microbiol. 11:762.

doi: 10.3389/fmicb.2020.00762

\section{Lactonase Specificity Is Key to Quorum Quenching in Pseudomonas aeruginosa}

\author{
Benjamin Rémy ${ }^{1,2}$, Laure Plener ${ }^{2}$, Philippe Decloquement ${ }^{1}$, Nicholas Armstrong ${ }^{1}$, \\ Mikael Elias ${ }^{3 *}$, David Daudé ${ }^{*}$ and Éric Chabrière ${ }^{1 *}$
}

\begin{abstract}
' Aix Marseille University, Institut de Recherche pour le Développement, Assistance Publique - Hôpitaux de Marseille, Microbes Evolution Phylogeny and Infections, Institut Hospitalo-Universitaire-Méditerranée Infection, Marseille, France, ${ }^{2}$ Gene\&GreenTK, Marseille, France, ${ }^{3}$ Department of Biochemistry, Molecular Biology and Biophysics - BioTechnology Institute, University of Minnesota, St. Paul, MN, United States
\end{abstract}

The human opportunistic pathogen Pseudomonas aeruginosa orchestrates the expression of many genes in a cell density-dependent manner by using quorum sensing (QS). Two acyl-homoserine lactones (AHLs) are involved in QS circuits and contribute to the regulation of virulence factors production, biofilm formation, and antimicrobial sensitivity. Disrupting QS, a strategy referred to as quorum quenching (QQ) can be achieved using exogenous AHL-degrading lactonases. However, the importance of enzyme specificity on quenching efficacy has been poorly investigated. Here, we used two lactonases both targeting the signal molecules $\mathrm{N}$-(3-oxododecanoyl)-Lhomoserine lactone (3-oxo- $\mathrm{C}_{12} \mathrm{HSL}$ ) and butyryl-homoserine lactone $\left(\mathrm{C}_{4} \mathrm{HSL}\right)$ albeit with different efficacies on $\mathrm{C}_{4} \mathrm{HSL}$. Interestingly, both lactonases similarly decreased AHL concentrations and comparably impacted the expression of AHL-based QS genes. However, strong variations were observed in Pseudomonas Quinolone Signal (PQS) regulation depending on the lactonase used. Both lactonases were also found to decrease virulence factors production and biofilm formation in vitro, albeit with different efficiencies. Unexpectedly, only the lactonase with lower efficacy on $\mathrm{C}_{4} \mathrm{HSL}$ was able to inhibit $P$. aeruginosa pathogenicity in vivo in an amoeba infection model. Similarly, proteomic analysis revealed large variations in protein levels involved in antibiotic resistance, biofilm formation, virulence and diverse cellular mechanisms depending on the chosen lactonase. This global analysis provides evidences that $\mathrm{QQ}$ enzyme specificity has a significant impact on the modulation of QS-associated behavior in $P$. aeruginosa PA14.

Keywords: quorum sensing, Pseudomonas aeruginosa, quorum quenching, acyl-homoserine lactones, lactonases, virulence, biofilm

\section{INTRODUCTION}

The human pathogen Pseudomonas aeruginosa is commonly involved in healthcare associated infections and frequently displays drug or multidrug resistance (Sievert et al., 2013; Weiner et al., 2016). This latter constitutes a serious therapeutic threat. Yet, the quest for new alternative treatments to fight bacterial infections is highly challenging. Disruption of quorum sensing (QS), 
a cell-density dependent communication system used by this bacterium to regulate the expression of several traits including virulence, has emerged as a non-bactericidal curative approach to address issues of antibiotics resistance (Fuqua and Greenberg, 2002; Bzdrenga et al., 2017; Rémy et al., 2018).

In Pseudomonas aeruginosa, three main QS systems have been described namely Las, Rhl, and PQS (i.e., Pseudomonas Quinolone Signal) involving the signal synthases LasI, RhlI, PqsABCDEH, and the receptors LasR, RhlR, and PqsR, respectively (Lee and Zhang, 2015; Papenfort and Bassler, 2016). These systems used three signaling molecules referred to as autoinducers. Two acyl-homoserines lactones (AHL) $\mathrm{N}$-(3-oxododecanoyl)-L-homoserine lactone (3-oxo- $\mathrm{C}_{12}$ HSL) and butyryl-homoserine lactone ( $\mathrm{C}_{4} \mathrm{HSL}$ ) are used by Las and Rhl systems while PQS is based on 2-alkyl-4-quinolones (Lee and Zhang, 2015; Papenfort and Bassler, 2016). These systems are interconnected and Las is considered as the global activator of all three systems (Latifi et al., 1996; Déziel et al., 2004).

Interferences with QS are termed quorum quenching (QQ) and mainly involve chemical inhibitors (QSIs) or autoinducer degrading enzymes (Grandclément et al., 2016; Rémy et al., 2018). QQ enzymes able to target AHLs belong to three classes: lactonases (EC 3.1.1), acylases (EC 3.5.1) and oxidoreductases (EC 1). Among lactone-degrading enzymes, paraoxonases, metallo- $\beta$-lactamase like lactonases (MLL) and phosphotriesterase-like lactonases (PLL) are the main studied families (Elias and Tawfik, 2012). They share a common catalytic mechanism and their differences in AHL substrate preference mainly lie on how the acyl chain can be accommodated into the catalytic site (Elias and Tawfik, 2012; Bergonzi et al., 2019).

In this study, we investigated the effects of two QQ lactonases with distinct AHL specificities, from PLL and MLL families, on $P$. aeruginosa PA14. We used W263I variant of SsoPox, an engineered variant of a PLL isolated from the thermophilic archaea Saccharolobus solfataricus (previously Sulfolobus solfataricus) that favors long aliphatic lactones as substrates, such as 3 -oxo-C 12 HSL (Hiblot et al., 2013). Its QQ efficiency for biofilm and virulence factors reduction was previously demonstrated in $P$. aeruginosa with two model strains (PAO1 and PA14) and 51 clinical isolates (Hraiech et al., 2014; Guendouze et al., 2017). This lactonase was also shown to reduce mortality in a rat pneumonia model (Hraiech et al., 2014). The MLL GcL isolated from Parageobacillus caldoxylosilyticus which was recently characterized and exhibits broad AHL specificity was chosen as the second lactonase (Bergonzi et al., 2016, 2019; Mahan et al., 2020). SsoPox W263I and $G c \mathrm{~L}$, which mainly differ in their ability to hydrolyze $\mathrm{C}_{4}$ HSL, were used independently and in combination, to disrupt QS of $P$. aeruginosa PA14 and to investigate the role of lactonase specificity on phenotypes, gene expression and proteome regulation. This work constitutes an extensive molecular and phenotypic comparative study of enzyme-based QQ in P. aeruginosa which highlight the importance of lactonase specificity in QQ treatment.

\section{RESULTS}

\section{Lactonase Specificity on $P$. aeruginosa AHLs}

Using an in vitro colorimetric assay, the ability of SsoPox W263I and $G c \mathrm{~L}$ to degrade synthetic $P$. aeruginosa AHLs was first investigated and the kinetic parameters of both enzymes were determined (Table 1). GcL efficiently hydrolyzed both $\mathrm{C}_{4}$ and 3-oxo-C 12 HSL, whereas SsoPox W263I efficiently degraded 3oxo- $\mathrm{C}_{12}$ HSL but exhibited poor activity toward $\mathrm{C}_{4} \mathrm{HSL}$ as indicated by $k_{\text {cat }} / K_{M}$ values. SsoPox W263I is 930 times more specific for 3-oxo- $\mathrm{C}_{12}$ than for $\mathrm{C}_{4}$ HSL whereas $G c \mathrm{~L}$ displays catalytic efficiencies $\left(k_{\mathrm{cat}} / K_{\mathrm{M}}\right)$ in the same order of magnitude for both substrates. While both enzymes demonstrated similar catalytic efficiencies on 3-oxo-C 12 HSL, SsoPox W263I showed stronger affinity for this substrate than GcL (lower $K_{\mathrm{M}}$ ). Moreover, enzymes strongly diverged regarding their ability to degrade $\mathrm{C}_{4} \mathrm{HSL}$ by more than two order of magnitude in favor of GcL. At saturating concentration of substrate, GcL and SsoPox showed only a 3 -fold difference in specific activities (U.mg ${ }^{-1}$ ) on 3-oxo-C 12 HSL, while GcL displayed a 133-fold higher activity on $\mathrm{C}_{4}$ HSL as compared to SsoPox W263I in the conditions used for this experiment. Although, it can also degrade $\mathrm{C}_{4}$ HSL, SsoPox W263I is mainly active on 3-oxo- $\mathrm{C}_{12}$ HSL while GcL can almost equally degrade both substrates. To take into account protein addition in the culture medium, SsoPox variant 5A8, which demonstrated no detectable activity on any AHL (Table 1) was used as a negative control, in the same amounts as active enzymes (Bergonzi et al., 2019).

\section{Both Quorum Quenching Lactonases Similarly Impact AHL Systems but Differently Influence PQS}

To decipher the impact of lactonases, mainly differing in their activity toward $\mathrm{C}_{4}$ HSL, on the QQ of PA14, SsoPox W263I and $G c \mathrm{~L}$ were used, alone or in combination, at adjusted concentrations in order to have the same activity regarding the substrate 3 -oxo- $\mathrm{C}_{12}$ HSL (i.e., equal number of enzymatic Units per volume) in the MOPS minimal medium cultures. PA14 growth in MOPS medium was followed over $26 \mathrm{~h}$. After $20 \mathrm{~h}$, cells in the culture reached stationary phase in all tested conditions (Supplementary Figure 1). Moreover, lactonase activities in the culture medium were not impacted after $20 \mathrm{~h}$, therefore this time point was chosen for further experiments (Supplementary Figure 2).

In order to evaluate the respective impact of both lactonases, alone or in combination, on AHL quantities, the concentration of both $\mathrm{C}_{4}$ HSL and 3-oxo- $\mathrm{C}_{12}$ HSL in the culture medium was estimated using reporter strains. Surprisingly, although the lactonases were proved to have very distinct specificity toward AHLs, neither $\mathrm{C}_{4}$ HSL nor 3-oxo- $\mathrm{C}_{12}$ HSL were detectable (Figures 1A,C). To further investigate the potential different role of the lactonases on PA14 regulation, the expression of major QS genes was monitored by RT-qPCR. Consistently 
TABLE 1 | Kinetic parameters of SsoPox W263l, SsoPox 5A8 and GCL for 3-oxo-C 12 HSL and C 4 HSL.

\begin{tabular}{|c|c|c|c|c|c|c|}
\hline \multirow{2}{*}{$\begin{array}{l}\text { Enzyme } \\
\text { AHL }\end{array}$} & \multicolumn{2}{|c|}{ SsoPox W263I } & \multicolumn{2}{|c|}{ GcL } & \multicolumn{2}{|c|}{ SsoPox $5 A 8$} \\
\hline & 3-oxo-- $\mathrm{C}_{12} \mathrm{HSL}$ & $\mathrm{C}_{4} \mathrm{HSL}$ & 3-oxo- $\mathrm{C}_{12}$ HSL & $\mathrm{C}_{4} \mathrm{HSL}$ & 3-oxo-C ${ }_{12}$ HSL & $\mathrm{C}_{4} \mathrm{HSL}$ \\
\hline$K_{\mathrm{M}}(\mu \mathrm{M})$ & $40 \pm 10$ & $(4.3 \pm 0.1) \times 10^{3}$ & $97 \pm 9$ & $(9.8 \pm 0.7) \times 10^{2}$ & N.D. & N.D. \\
\hline$k_{\text {cat }}\left(s^{-1}\right)$ & $2.9 \pm 0.1$ & $0.37 \pm 0.01$ & $10 \pm 1$ & $43 \pm 1$ & N.D. & N.D. \\
\hline$k_{\text {cat }} / K_{M}\left(M^{-1} \cdot s^{-1}\right)$ & $(8 \pm 2) \times 10^{4}$ & $86 \pm 1$ & $(1.1 \pm 0.1) \times 10^{5}$ & $(4.3 \pm 0.3) \times 10^{4}$ & N.D. & N.D. \\
\hline Specificity ratio* & \multicolumn{2}{|c|}{930} & \multicolumn{2}{|c|}{2.5} & \multicolumn{2}{|c|}{-} \\
\hline Specific activity $\left(\cup \cdot \mathrm{mg}^{-1}\right)^{\star \star}$ & $4.3 \pm 0.5$ & $0.46 \pm 0.02$ & $13 \pm 2$ & $61 \pm 1$ & N.D. & N.D. \\
\hline Activity ratio ${ }^{\star \star \star}$ & - & - & 3.0 & 133 & - & - \\
\hline
\end{tabular}

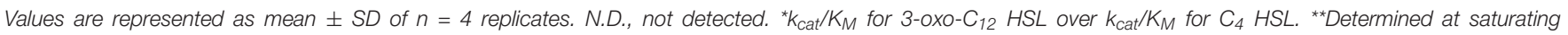
concentration of each AHL. ${ }^{* *}$ Specific activity of GCL over specific activity of SsoPox W263I.

with AHL measurements, both enzymes similarly impacted Las and Rhl systems (Figures 1B,D). lasR expression was significantly decreased while lasI expression was not impacted and the expression of both $r h l I$ and $r h l R$ was significantly decreased. Nevertheless, strong variations between lactonases were observed regarding PQS system. Although, $p q s R$ expression was decreased by both lactonases, a major difference arose for $p q s A$, a gene involved in the synthesis of the PQS autoinducer (Figure 1F). pqsA expression was strongly reduced with SsoPox W263I, whereas GcL did not impact pqsA transcript levels as compared to the controls. When treated with both enzymes combined, $p q s A$ expression followed the same trend as with SsoPox W263I alone with a strong decrease in transcript levels (Figure 1F). To confirm these observations at the molecular level, the amount of 2-heptyl-3,4-dihydroxyquinoline (PQS) was measured in culture supernatants. PQS concentration drastically dropped after treatment with SsoPox W263I alone or combined with $G c \mathrm{~L}$ as compared to controls and treatment with $G c \mathrm{~L}$ alone (Figure 1E). Interestingly, the level of 4-hydroxy-2heptylquinoline (HHQ), a precursor of PQS, was also affected and was mainly detected in culture supernatants of PA14 treated by $G c \mathrm{~L}$ alone $(1.5 \mu \mathrm{M})$ as compared to other conditions $(<0.15 \mu \mathrm{M})$ (Supplementary Figure 3).

Altogether, these results demonstrate that lactonases with distinct AHL specificities similarly impacted the tested AHLbased systems but yielded significant changes in PQS production and regulation. To further probe the impact of these variations on PA14 behavior, phenotypic characterization was performed.

\section{Both Quorum Quenching Lactonases Inhibit the Production of Virulence Factors in vitro}

Three representative virulence factors of $P$. aeruginosa, namely pyocyanin, protease and elastase were measured with different enzyme concentrations and combinations. Protease and elastase production decreased with increasing lactonase concentrations, while the addition of inactive variant had no effect (Figures 2A,B). Pyocyanin production slightly increased for the lowest concentrations of enzymes and decreased from 0.04 U.mL $\mathrm{mL}^{-1}$ (Figure 2C). The highest concentration of enzymes reduced the production of elastase by more than $75 \%$ and the production of pyocyanin and protease by more than $95 \%$ in all conditions. GcL significantly reduced the production of all three virulence factors at lower concentrations than SsoPox W263I (0.04 U.mL $\mathrm{mL}^{-1}$ versus $\left.0.4 \mathrm{U} \cdot \mathrm{mL}^{-1}\right)$. Furthermore, the combination of the two lactonases showed combinatory effects and decreased pyocyanin and protease from 0.004 U.mL $L^{-1}$ as compared to each enzyme alone (Figures 2A,C).

Reduction of in vitro virulence factor production was thus achieved with both enzymes, GcL being efficient at lower concentrations than SsoPox W263I and the combination of both lactonases showed synergistic effect particularly regarding protease inhibition.

\section{The Two Quorum Quenching Lactonases Have Differential Abilities to Inhibit in vitro Biofilm Formation and Biofilm-Associated Tolerance to Antimicrobials}

Biofilm formation was reduced in a dose-dependent manner in every condition (Figure 3). However, SsoPox W263I showed a greater anti-biofilm effect than GcL. SsoPox W263I nearly completely inhibited biofilm formation (reduction $>99 \%$ for SsoPox W263I and of $76 \%$ for GcL at 2 U.mL ${ }^{-1}$ ) whereas small bacterial aggregates were still observable with $G c \mathrm{~L}$ even when increasing the concentration up to $7 \mathrm{U} \cdot \mathrm{mL}^{-1}$ (Figure 3). The simultaneous utilization of both enzymes showed a combinatory effect at 0.004 U.mL ${ }^{-1}$ as compared to each enzyme alone and inhibited biofilm like SsoPox W263I alone, and unlike GcL, at high concentration.

As biofilm may reduce antimicrobial molecules efficacy, we evaluated the role of QQ to increase bacterial susceptibility to antiseptics and antibiotics. Using the minimal biofilm eradication concentration (MBEC) assay, the sensitivity of PA14 biofilms to antimicrobials following lactonase exposure was determined for tobramycin and gentamicin as well as for $\mathrm{H}_{2} \mathrm{O}_{2}$ (Harrison et al., 2010). In this assay, only adherent cells grown on a peg support are transferred and exposed to antimicrobials. Without antimicrobial application, similar cell quantities were recovered from the peg lid support in every condition (Supplementary Figure 4). However, after pretreatment with SsoPox W263I, PA14 was more sensitive to all three of these antimicrobial agents (Table 2 and Supplementary Figure 4). For PA14 pretreated with SsoPox W263I, the MBEC values were reduced by 10 -fold after 

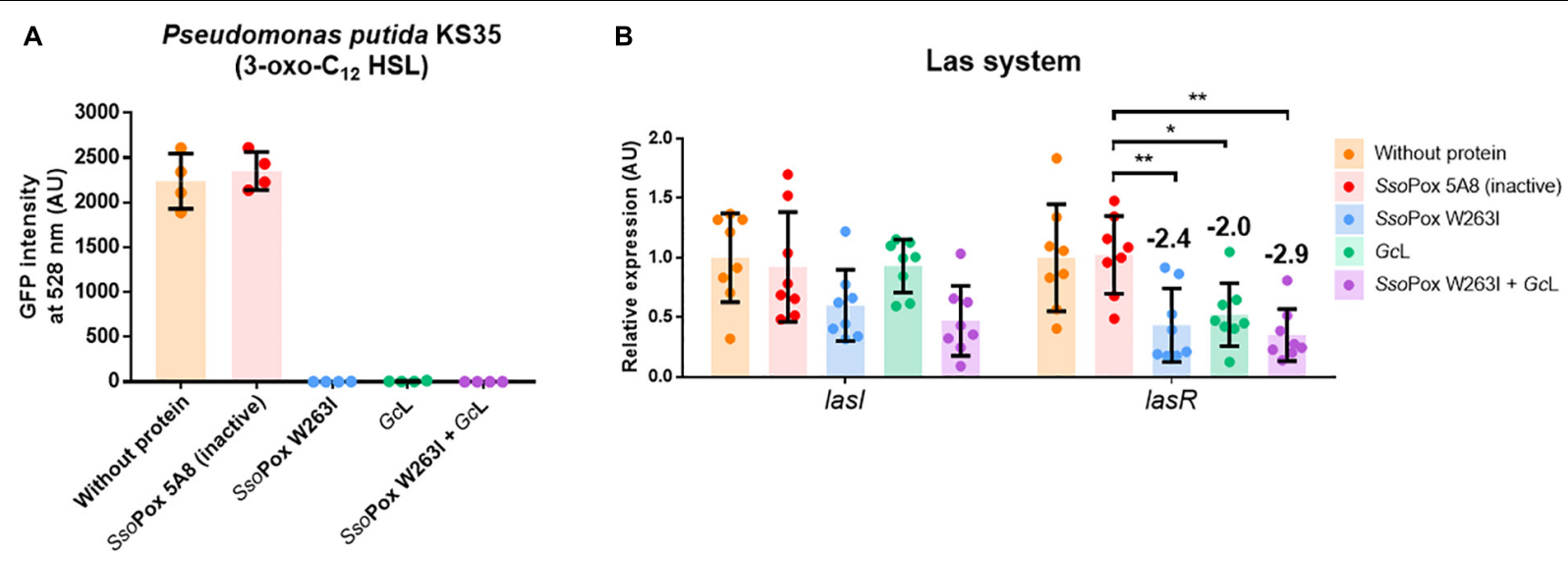

C

Chromobacterium violaceum CV026 D $\left(\mathrm{C}_{4} \mathrm{HSL}\right)$
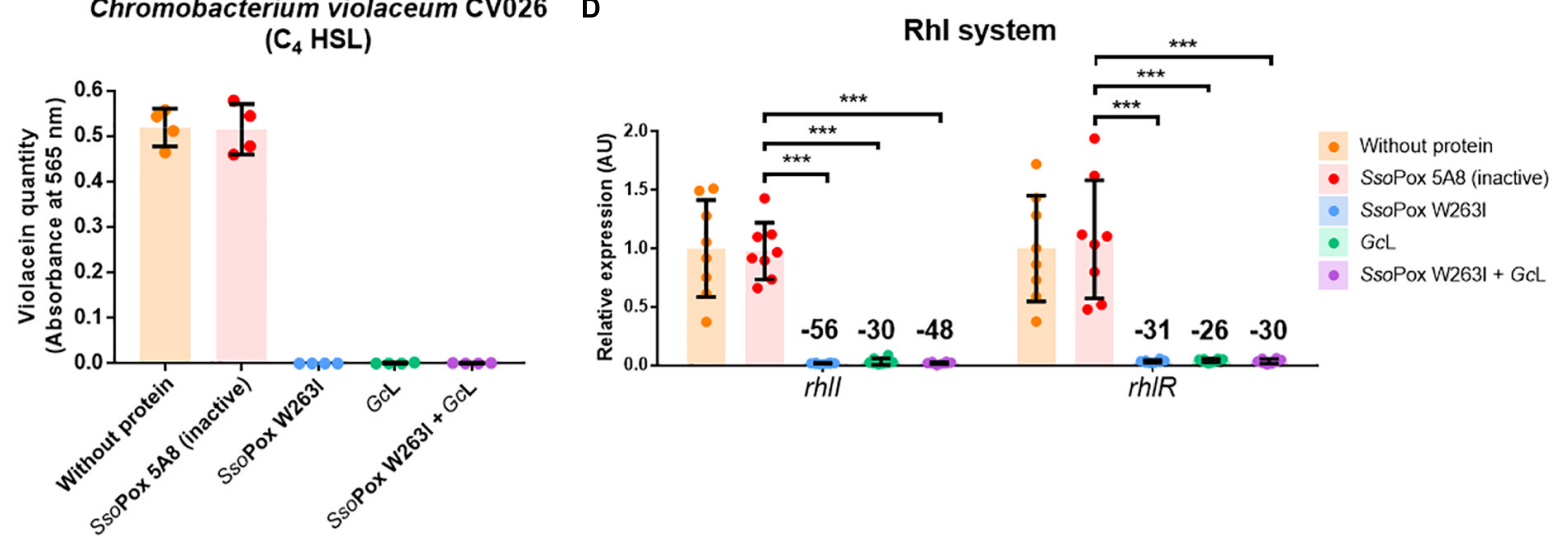

E

PQS

$\mathbf{F}$
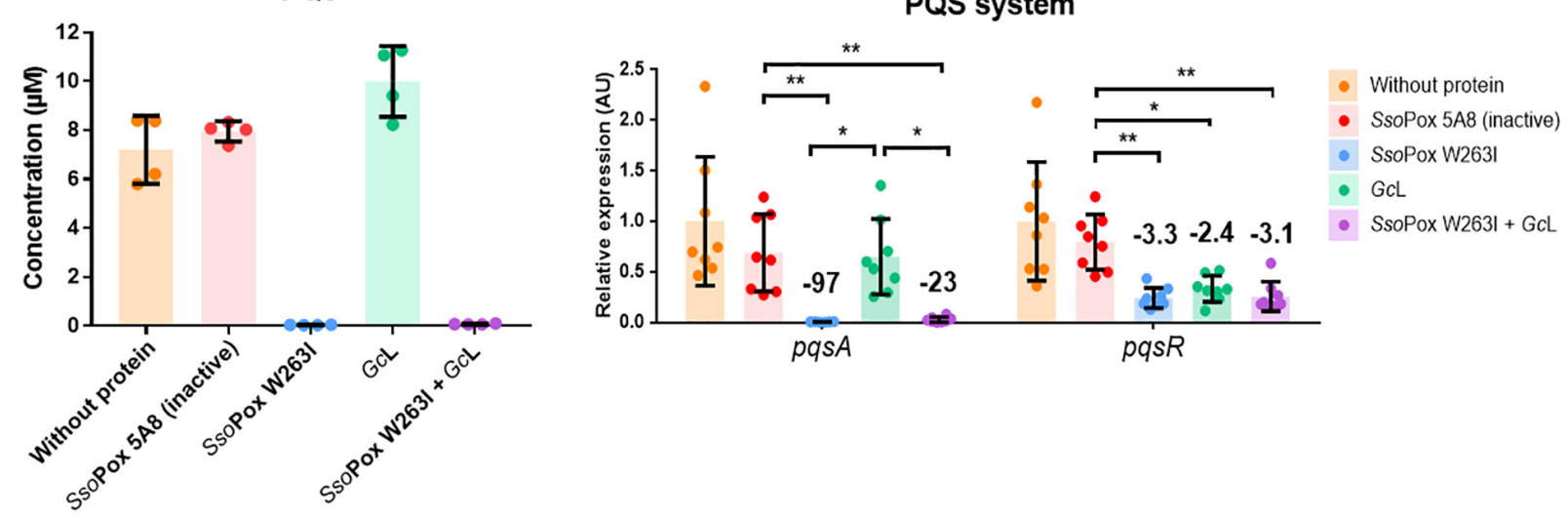

FIGURE 1 | QS molecules and QS gene expression are similarly impacted by the two lactonases except for PQS and its associated synthesis pathway. For each active enzyme or their mixture, $2 \mathrm{U} \cdot \mathrm{mL}^{-1}$ activity on $3-0 x \mathrm{O}-\mathrm{C}_{12} \mathrm{HSL}$ was used during culture step. The inactive variant SsoPox $5 \mathrm{~A} 8$ was used at the same protein

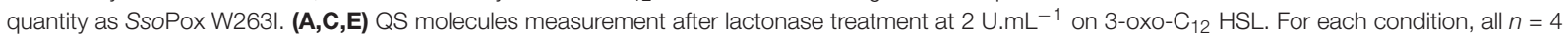

independent samples are plotted with mean and standard deviation in colored histogram and black bars. (B,D,F) Relative expression of genes involved in Las, Rhl, and PQS systems after lactonase treatment at $2 \mathrm{U} \cdot \mathrm{mL}^{-1}$ on $3-\mathrm{oxo}_{-} \mathrm{C}_{12} \mathrm{HSL}$. The inactive variant SsoPox $5 \mathrm{~A} 8$ was added in the same protein quantity as SsoPox W263I. All $n=8$ independent samples are plotted with mean and standard deviation as colored histograms and black bars. Statistical significance according to Sidak's multiple comparison test was highlighted by black stars (multiplicity adjusted $p_{\text {value }}<0.05^{\star},<0.01^{\star \star},<0.001^{\star \star \star}$ ). When significantly different from the inactive SsoPox $5 \mathrm{~A} 8$ control, fold change was added on top of the data.

relatively short exposure periods of $1.5 \mathrm{~h}$ to $\mathrm{H}_{2} \mathrm{O}_{2}$ and $3 \mathrm{~h}$ for antibiotics. GcL, in contrast, only impacted $\mathrm{H}_{2} \mathrm{O}_{2}$ sensitivity with a 2 -fold reduction of the MBEC value (Table 2). The combined pretreatment with both lactonases increased sensitivity for all three antimicrobials with a similar-fold change as SsoPox W263I alone (Table 2 and Supplementary Figure 4). QQ enzymes 


\section{Proteolytic activity}

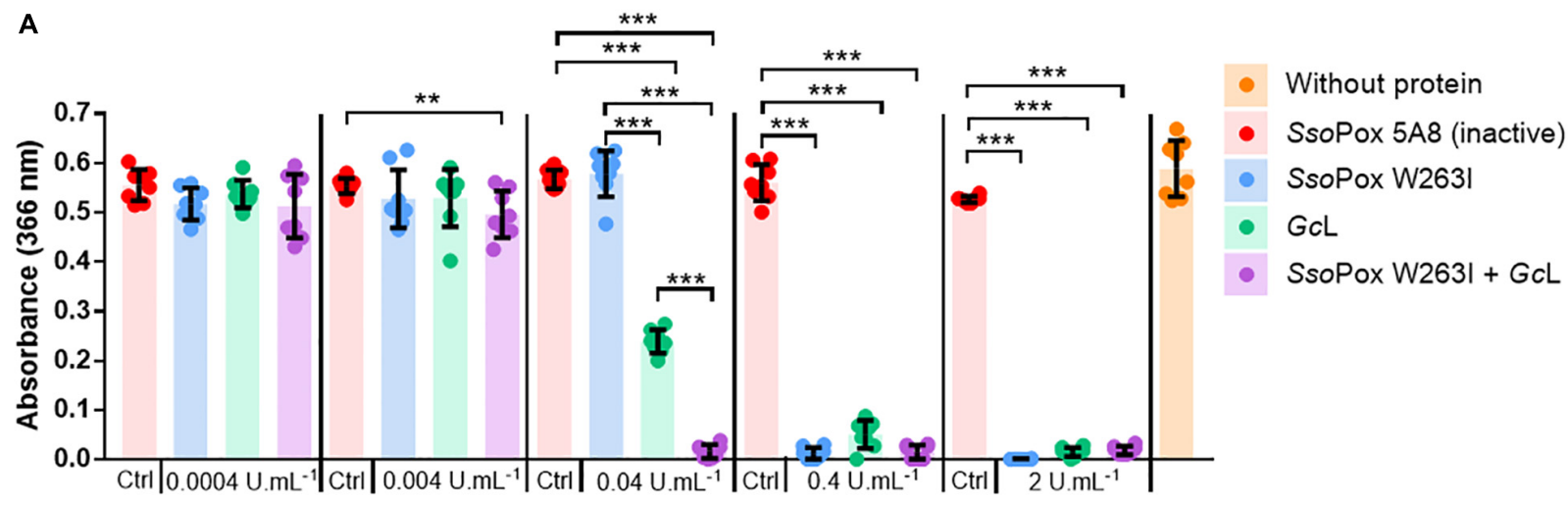

B

Elastolytic activity

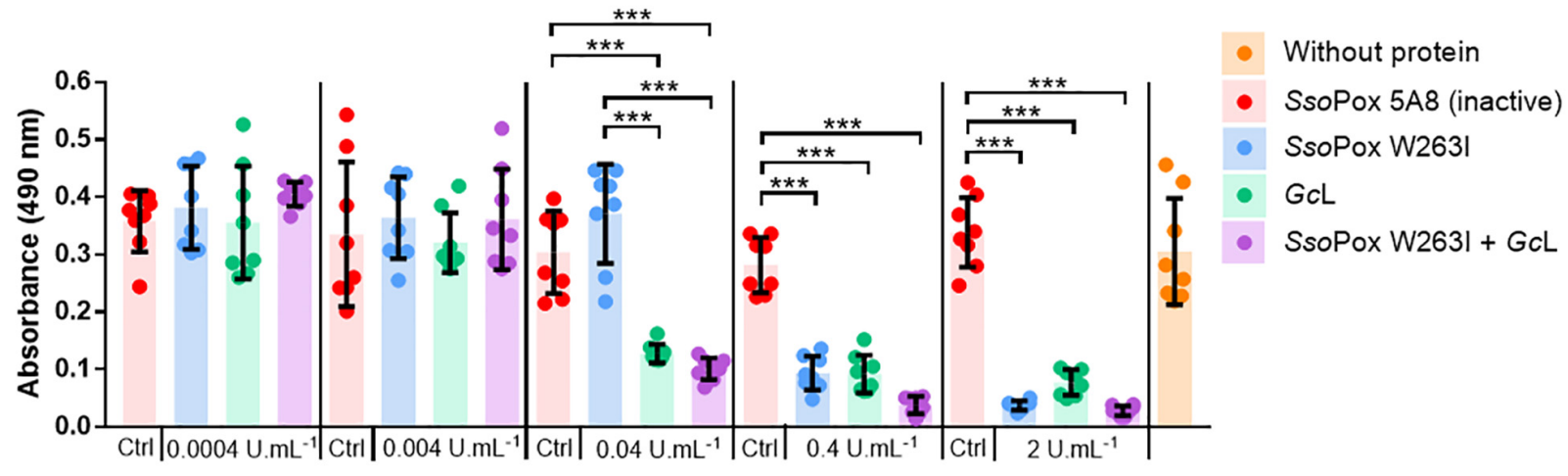

C

\section{Pyocyanin}

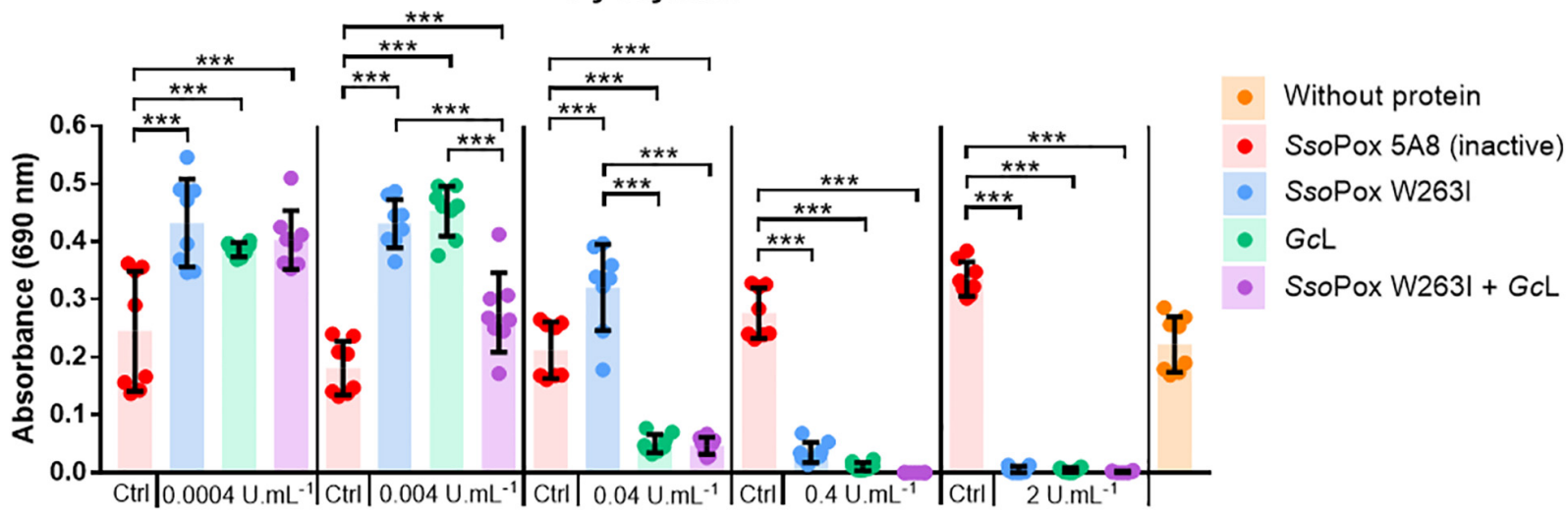

FIGURE 2 | In vitro virulence factors are reduced by the two lactonases alone or in combination. (A-C) Proteases, elastase B, pyocyanin measurements after lactonase treatment. For each active enzyme or their mixture, an equivalent activity on 3-oxo- $\mathrm{C}_{12} \mathrm{HSL}$ was used. The inactive variant SsoPox $5 \mathrm{~A} 8$ was used at the same protein quantity as SsoPox W263l. All $n=8$ independent samples are plotted with their mean and standard deviation as colored histograms and black bars. Statistical significance according to Holm-Sidak's multiple comparison test are highlighted by black stars (multiplicity adjusted $p_{\text {value }}<0.05^{\star},<0.01^{\star \star},<0.001^{\star \star \star}$ ).

thus enhanced the efficacy of antimicrobial treatments in PA14. However, SsoPox W263I exhibited much greater ability than GcL (from 5- to 10-fold) to increase antimicrobial sensitivity of $P$. aeruginosa biofilms.
Biofilm formation and associated antimicrobial sensitivity were differently impacted by lactonases. Only SsoPox W263I decreased biofilm formation below detection limit and lowered MBEC values for both antibiotics and $\mathrm{H}_{2} \mathrm{O}_{2}$. Combining both 


\section{A}

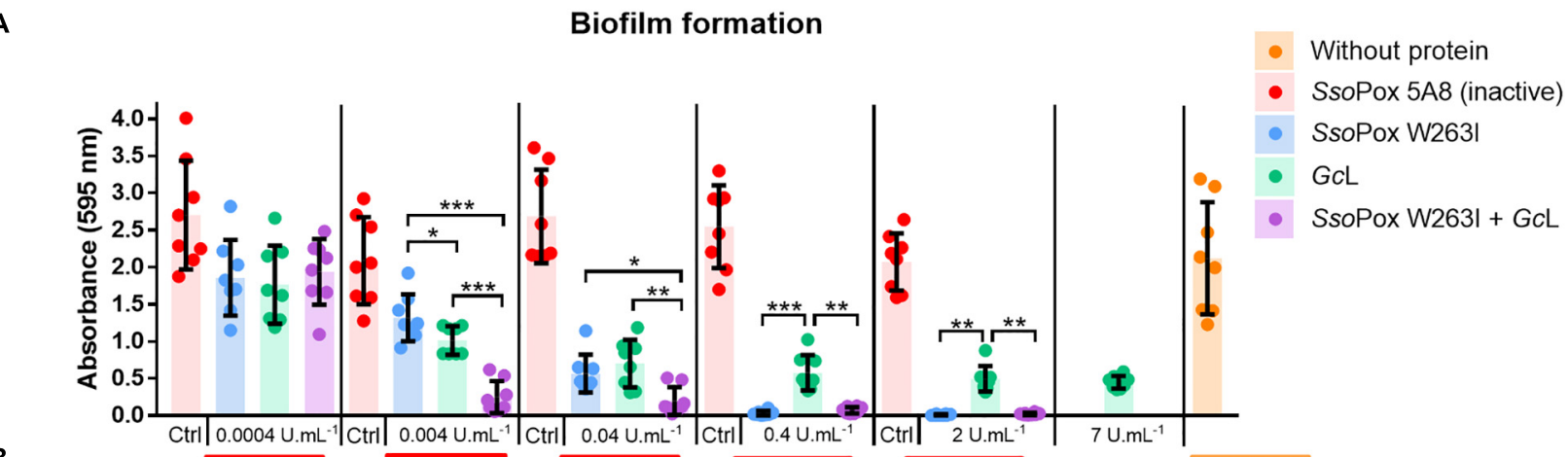

B
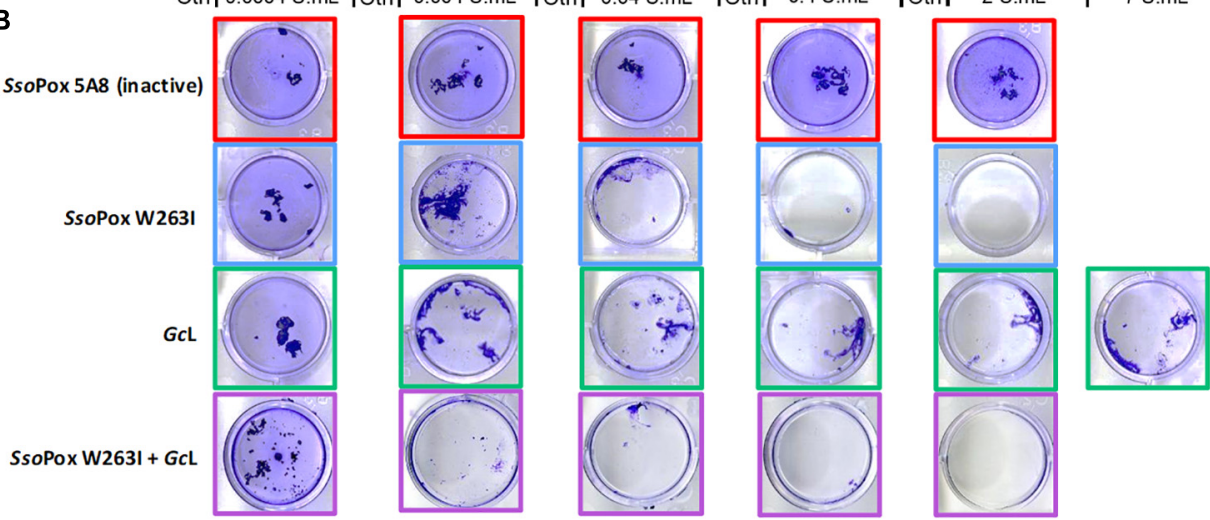

FIGURE 3 | Biofilm formation is reduced by GcL and undetectable with SsoPox W263I. (A) Biofilm formation was measured using crystal violet staining. For each active enzyme or their mixture, an equivalent activity on 3-oxo- $\mathrm{C}_{12} \mathrm{HSL}$ was used. The inactive variant SsoPox $5 \mathrm{~A} 8$ was used at the same protein quantity as SsoPox W263l. All $n=8$ independent samples are plotted with their mean and standard deviation as colored histograms and black bars. Statistical significance according to Holm-Sidak's multiple comparison test are highlighted by black stars (multiplicity adjusted $p_{\text {value }}<0.05^{\star},<0.01^{\star \star},<0.001^{\star \star \star}$ ). (B) Corresponding pictures of crystal violet stained biofilm after lactonase treatment for each concentration and conditions.

lactonases showed similar results than SsoPox W263I used alone with no synergistic effect observed.

\section{Both Quorum Quenching Lactonases Reduce Competing Capability of $P$. aeruginosa Toward Escherichia coli}

The capacity of PA14 to compete with other prokaryotes was evaluated using Escherichia coli as bacterial competitor over 24 h (Allsopp et al., 2017). In the absence of QQ treatments, PA14 reduced the population of living E. coli by more than 10 -fold as compared to E. coli alone (Figure 4). However, with any QQ treatment at $2 \mathrm{U} \cdot \mathrm{mL}^{-1}, E$. coli was not killed and a similar number of living cells were recovered as to

TABLE 2 | MBEC values for the three antimicrobials tested with lactonases at 2 U. $\mathrm{mL}^{-1}$ on $3-\mathrm{OxO}^{-\mathrm{C}_{12}} \mathrm{HSL}$.

\begin{tabular}{lcccc}
\hline MBEC & $\begin{array}{c}\text { SsoPox 5A8 } \\
\text { (inactive) }\end{array}$ & $\begin{array}{c}\text { SsoPox } \\
\text { W263I }\end{array}$ & GcL & $\begin{array}{c}\text { SsoPox } \\
\text { W263I + GcL }\end{array}$ \\
\hline $\mathrm{H}_{2} \mathrm{O}_{2}[\mathrm{mM}]$ & 100 & 10 & 50 & 10 \\
Tobramycin $\left[\mu \mathrm{g} \cdot \mathrm{mL}^{-1}\right]$ & 10 & 1 & 10 & 1 \\
Gentamicin $\left[\mu \mathrm{g} \cdot \mathrm{mL}^{-1}\right]$ & 20 & 2 & 20 & 2 \\
\hline
\end{tabular}

${ }^{*}$ Equivalent protein quantity as SsoPox W263I condition.
E. coli control (Figure 4). Thus, both QQ lactonases, alone or combined, reduced with similar magnitude the competition of $P$. aeruginosa against another prokaryote, regardless of their substrate specificity.

\section{Only the Lactonase With Substrate Preference for 3-Oxo- $\mathrm{C}_{12}$ HSL Reduces Virulence in an Amoeba Infection Model}

To evaluate the QQ impact of both lactonases on PA14 virulence toward a eukaryotic host, an in vivo amoeba assay was performed. This assay is based on the ability of Acanthamoeba polyphaga Linc AP1 to grow in the presence of quenched or non-quenched bacteria (Fenner et al., 2006; Mion et al., 2019). In both controls, amoebas were not able to grow in presence of PA14 demonstrating its virulence toward A. polyphaga (Figure 5). After quenching by SsoPox W263I, virulence toward amoebas was reduced in a dose-response manner and A. polyphaga was able to propagate even at the lowest enzyme concentration tested (Figure 5A). Conversely, GcL did not restore the ability of amoebas to grow, even at the highest concentrations (Figure 5B). Finally, when both enzymes were mixed, virulence was reduced to a degree comparable to that of SsoPox W263I alone (Figure 5C). Thus, in this eukaryotic virulence assay, these two lactonases with distinct substrate specificity had different impacts; SsoPox, even 


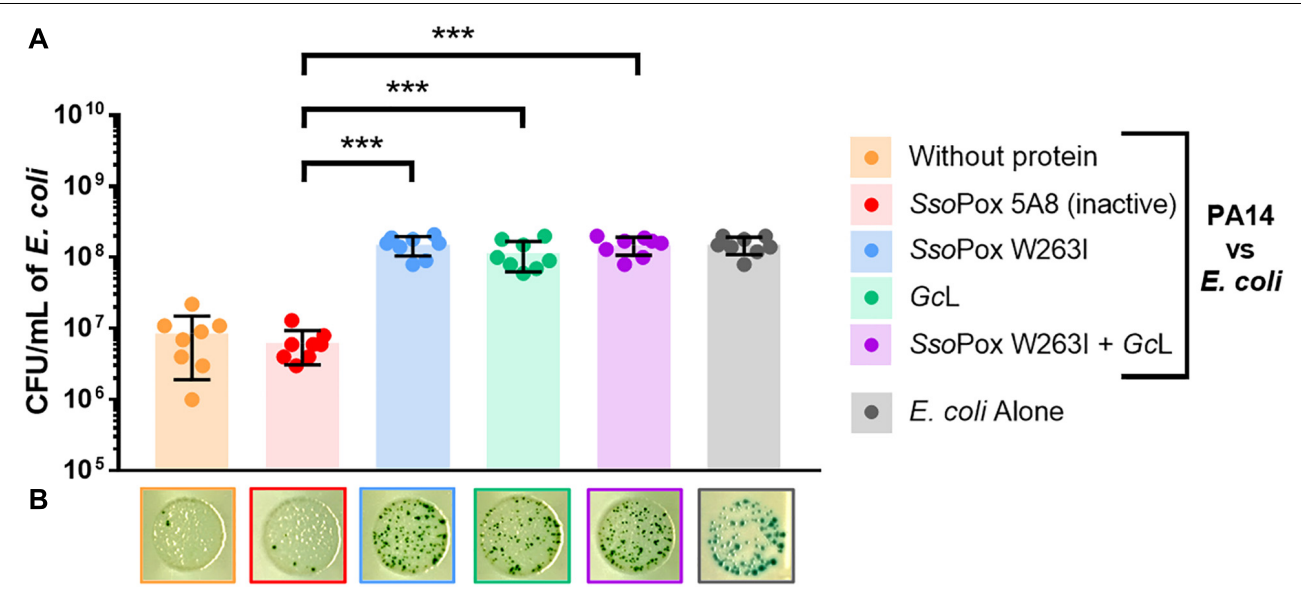

FIGURE 4 | PA14 virulence toward E. coli is similarly reduced by both lactonases. (A) CFU count of E. coli and PA14 recovered after 24 h of incubation. For each active enzyme or their mixture, $2 \mathrm{U} \cdot \mathrm{mL}^{-1}$ activity on $3-\mathrm{oxo}_{-} \mathrm{C}_{12} \mathrm{HSL}$ was used. The inactive variant SsoPox $5 \mathrm{~A} 8$ was used at the same protein quantity as SsoPox W263I. All $n=8$ independent samples are plotted with mean and standard deviation as colored histograms and black bars. Statistical significance according to Sidak's multiple comparison test was highlighted by black stars (multiplicity adjusted $p_{\text {value }}<0.05^{\star},<0.01^{\star \star},<0.001^{\star \star \star}$ ) for $E$. coli count at 24 h. (B) Pictures of a representative dilution for each condition where surviving $E$. coli are visible as dark blue colonies.

when used at 17,500-fold lower concentration, showed greater effects than $G c L$.

\section{Treatment of PA14 With Different Lactonases Leads to Distinct Proteomic Profiles}

To further investigate the specific effects of signal disruption by the two lactonases and get a broader picture of the differences observed on phenotypes, we conducted proteomic analyses on $P$. aeruginosa PA14 cultures. A total of 515 (8.7\%) out of the 5,886 proteins of PA14 were detected and identified (Uniprot database). The relative abundances of 210 proteins were significantly changed (fold change $\geq 2$ and $p_{\text {value }}<0.05$ ) in at least one of the six possible comparisons (Supplementary Dataset S1). This number is in the same range as previous reports investigating QSI effects by proteomic and transcriptomic analyses (Hentzer et al., 2003; Nalca et al., 2006; O'Loughlin et al., 2013; Sethupathy et al., 2016). It provides evidence of the great importance of signal disruption in the regulation of the PA14 proteome. Principal component analysis (PCA) of the 210 proteins resulted in 11 principal components with a cumulative explained variation $\left(R^{2} \mathrm{X}\right)$ of $98 \%$ and predicted variation $\left(Q^{2}\right)$ of $86 \%$ (Supplementary Figure 5). The two first components differentiate three distinct groups accounting for most of the sample variations (cumulated $R^{2} \mathrm{X}$ of $70 \%$ ) (Supplementary Figures $5 \mathrm{~A}, \mathrm{C}$ ). The first principal component highlights the significant difference between the control (SsoPox 5A8) and the three QQ treatments. The second principal component discriminates the treatments using either SsoPox W263I or both enzymes as opposed to $G c \mathrm{~L}$ alone.

The 210 proteins with altered abundance were clustered by biological functions according to PseudoCAP classification (Winsor et al., 2016) (Figure 6A). 29\% are associated with metabolic pathways including cofactor, nucleotide or amino acid biosynthesis, as well as the metabolism of energy, carbon compounds, or fatty acids. Proteins related to translation and post-translational modification as well as chaperones and heat shock proteins accounted for $14.3 \%$ of altered proteins. Membrane associated proteins represent $11.9 \%$ of the impacted proteins and specifically include porins and proteins involved in efflux or protein export. Other affected proteins relate to adaptation, protection and secreted factors (8.6\%) and transcriptional regulator or transcription related proteins classes $(5.7 \%)$. Changes of abundance in proteins involved in motility, attachments and chemotaxis (4.3\%), cell wall/LPS/capsule (2.9\%) and DNA processing and cell division (2.9\%) were also observed. Finally, the remaining impacted proteins $(20.5 \%)$ were categorized as hypothetical, unclassified, unknown proteins and putative enzymes.

Analyzing fold changes, strong variations were observed between GcL and SsoPox W263I treatments (Figure 6B). The impact of lactonases on QS-involved proteins was first evaluated. Although, LasI/R, RhlI/R, and PqsR proteins were not detected, probably due to concentrations below the detection limit of the method, proteins of the PQS synthesis pathway were detected and their level were strongly altered as a function of the used lactonase. The level of PqsD was only reduced with SsoPox W263I treatment (fold change of -5 and -7 vs. control and GcL respectively) whereas $\mathrm{PqsE}$, an effector protein encoded by the $p q s A B C D E$ operon but not mandatory for PQS synthesis, was found more abundantly in the proteomic profile of PA14 treated with $G c L$ (fold change of +17 and +44 vs. control and SsoPox W263I) (Drees and Fetzner, 2015; Rampioni et al., 2016).

Several proteins involved in biofilm formation were highlighted by the proteomic analysis. PA14_61190 (PA4624/CdrB), transporter of the adhesin CdrA, was decreased with both lactonases but to a stronger degree with SsoPox W263I as compared to $G c \mathrm{~L}$ (fold change of -13 and -2 vs. control and GcL) (Borlee et al., 2010; Reichhardt and Wong, 2018). 

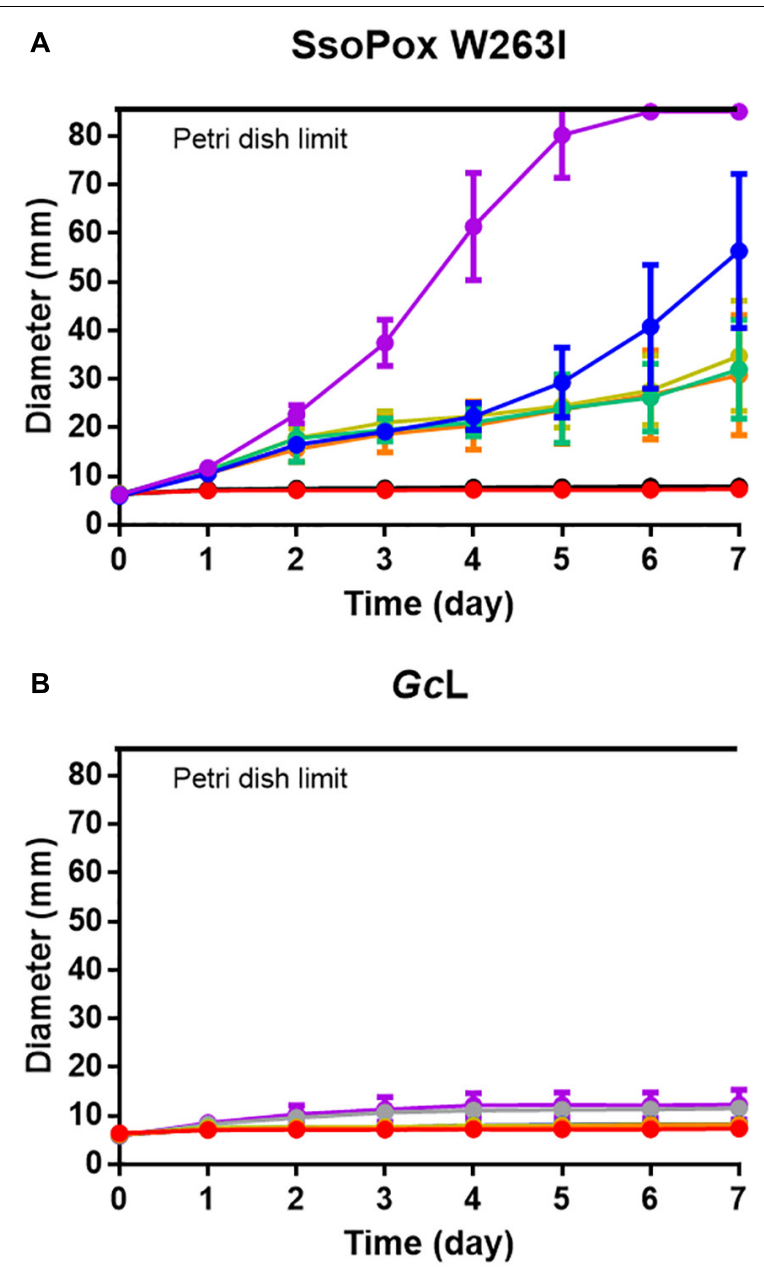

c SsoPox W263I+GcL
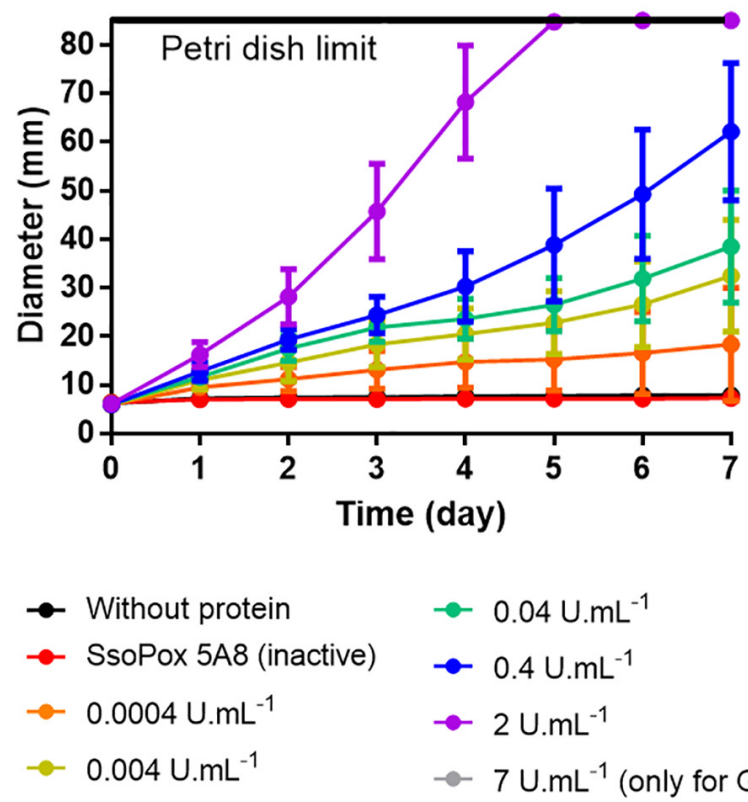

$\rightarrow 0.04$ U. $\mathrm{mL}^{-1}$

$\multimap 0.4$ U.mL $\mathrm{mL}^{-1}$

$\rightarrow 2 \cup \cdot \mathrm{mL}^{-1}$

- 7 U.mL $\mathrm{mL}^{-1}$ (only for GcL)

FIGURE 5 | Continued

FIGURE 5 | PA14 virulence toward amoeba is only reduced with SsoPox W263I. (A-C) Propagation of $A$. polyphaga Linc AP1 in virulence plate assay after treatment of $P$. aeruginosa PA14 by SsoPox W263I, GcL, SsoPox W263I and GCL. All $n=8$ independent samples are represented by the mean and standard deviation in corresponding colored bars. For each active enzyme or their mixture, an equivalent activity on $3-\mathrm{oxo}_{-} \mathrm{C}_{12} \mathrm{HSL}$ was used. The inactive variant SsoPox $5 \mathrm{~A} 8$ was used at the same protein quantity as SsoPox W263l at 2 U.mL $\mathrm{mL}^{-1}$

Similarly, the abundance of PA14_01490 (PA0122/RahU), a Rhl activated lipid binding protein, was decreased with both lactonase treatments but to a greater extent with SsoPox W263I (fold change of -959 and -107 vs. control and GcL) (Miklavič et al., 2015). Conversely, GcL induced a stronger decrease of Tsp (or AlgO), a protein part of alginate synthesis regulation, than SsoPox W263I (fold change of -115 and -35 vs. control and SsoPox W263I) (Qiu et al., 2007; Hay et al., 2014; Delgado et al., 2018). However, AlgU, the alginate regulator, and OprF, a pleiotropic porin also involved in biofilm formation, were only significantly reduced with SsoPox W263I (Hay et al., 2014; Chevalier et al., 2017). On the other hand, $\mathrm{Ndk}$, a protein related to alginate synthesis and DppA1, related to aggregation, were both only increased with GcL (Sundin et al., 1996; Kim et al., 1998; Lee et al., 2018).

Several proteins involved in oxidative stress response and antibiotic sensitivity exhibited a modified expression level. The abundance of three proteins (PA14_18690, OpdB, and OprG) were increased and seven others (PA14_47550, PA14_18330/50, ObgE, MexG, MexH, and OmpD) were reduced with both treatments as compared to the control (Aendekerk, 2005; Breidenstein et al., 2008; Dotsch et al., 2009; Balasubramanian et al., 2013; Verstraeten et al., 2015; Sakhtah et al., 2016; Chevalier et al., 2017; Gaviard et al., 2018; Wolloscheck et al., 2018). Several other protein levels showed differences between the two lactonase treatments. The abundance of five proteins (OprF, OprM, HflK, $\mathrm{OmpH}$, and Ppk) were reduced only with SsoPox W263I while two others (OprD and OprH) were increased only with GcL treatment (Fraley et al., 2007; Dotsch et al., 2009; Lister et al., 2009; Hinz et al., 2011; Somprasong et al., 2012; Chevalier et al., 2017; Sanz-García et al., 2019).

Regarding proteins associated with virulence, both lactonase treatments reduced the abundance of PA14_48590 and PA14_05510 (PA0423/PasP in PAO1) (Marquart et al., 2005; Feinbaum et al., 2012). SsoPox W263I and GcL also reduced the levels of phenazine synthesis pathway enzymes PhzB, D, $\mathrm{E}, \mathrm{F}$ and the known phenazine transporter MexGHI-OpmD as compared to the control (Sakhtah et al., 2016). Interestingly, a stronger reduction was observed with SsoPox W263I than with GcL on PhzB and D, as well as a drastic decrease of PhzM with SsoPox W263I only (fold change of -77 and -14 vs. control and $G c \mathrm{~L})$. Changes in protein abundance levels were also observed in type 3 secretion system (T3SS) structural and effector proteins (CtpA, PopD, SpcU, and ExoU), associated with virulence toward amoeba, they were more abundant upon treatment with $G c \mathrm{~L}$ as compared to SsoPox (Pukatzki et al., 2002; Matz et al., 2008; Seo and Darwin, 2013). Important fluctuations in the abundance of $\mathrm{H} 3$ type 6 secretion system (H3-T6SS) proteins, a system 
A

All significantly changed proteins

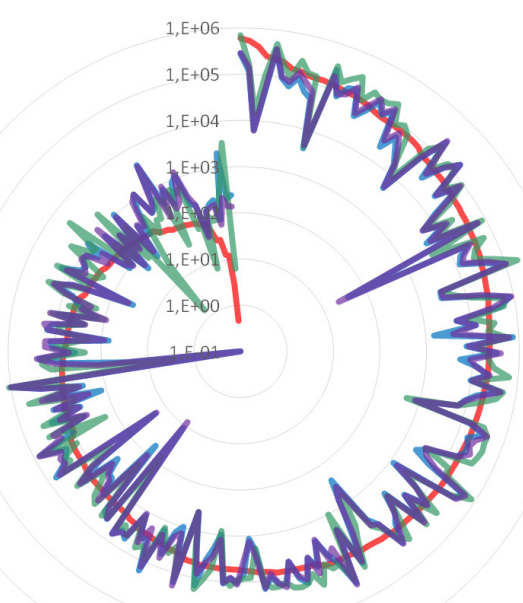

$n=210$

-SsoPox 5 A8 (Inactive)

$-\mathrm{GCL}$

-SsoPox W263I

-SsoPox W263I+ GCL

$$
n=9
$$

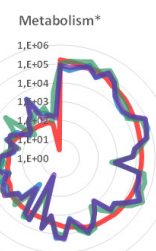

Hypothetical, unclassified, unknown

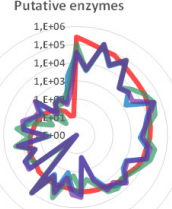

Translation, post-translational modification,

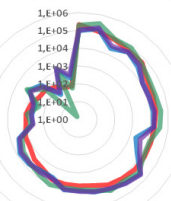
$n=61$
$n=43$
$n=30$

Transport of small molecules / Membrane

Adaptation, Protection / Secreted Factors (toxins, Protection / Secreted factor

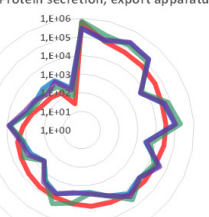

$n=25$

Motility \& Attachment / Chemotaxis / Two-component regulatory systems

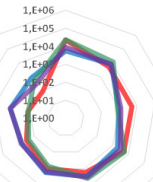

$$
\mathrm{n}=18
$$

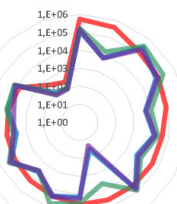

Cell wall / LPS / Capsule

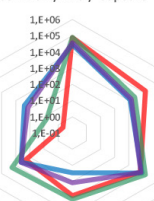

$n=6$ criptional factors / Tran scription, RNA

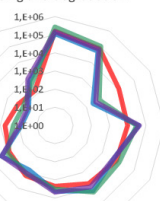

$\mathrm{n}=12$

DNA replication, recombination, modification and repair/ Cell division

B

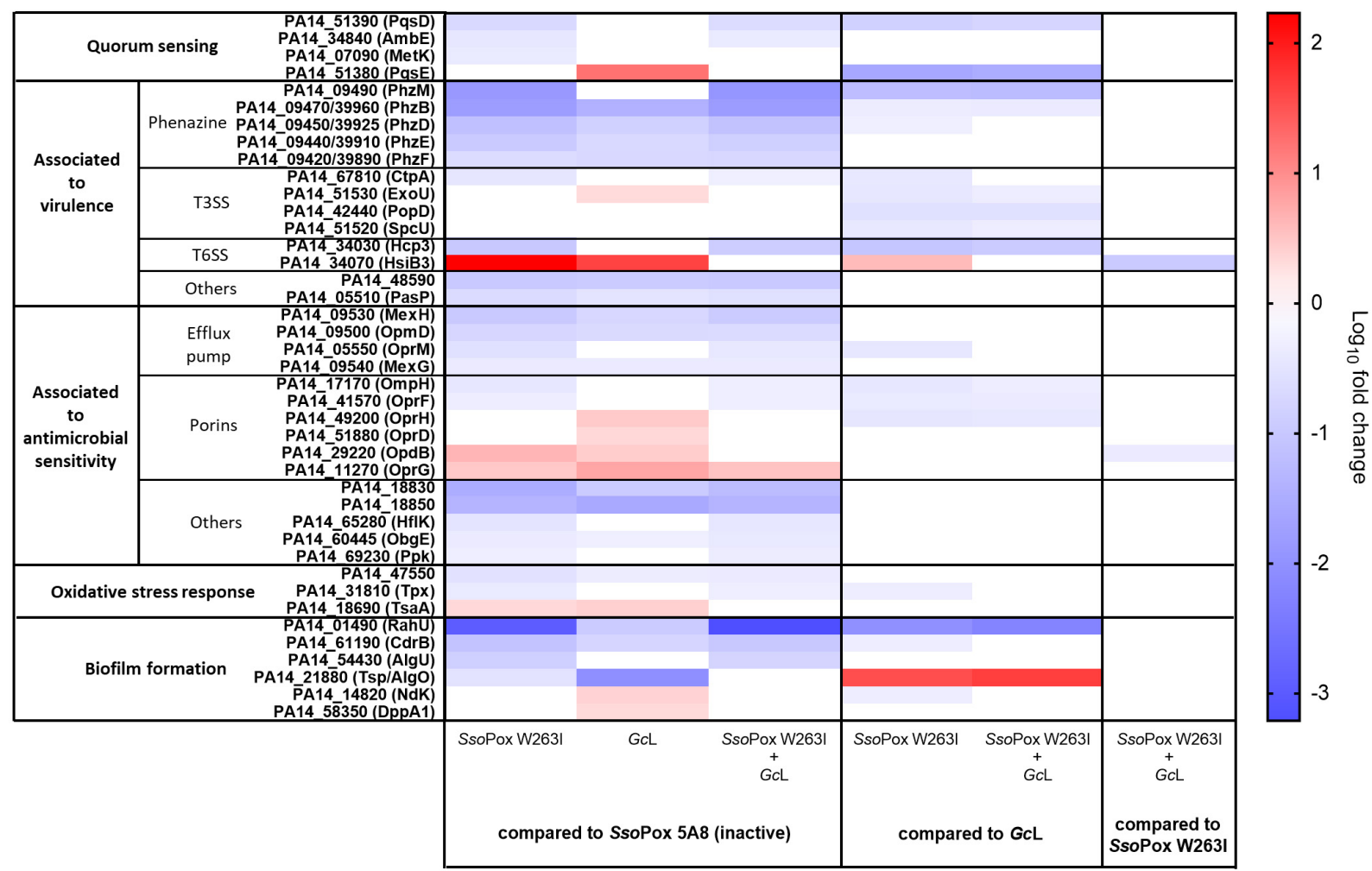

FIGURE 6 | Fluctuations in P. aeruginosa PA14 proteomes reflect enzyme-mediated phenotypic changes. For each active enzyme or their mixture, 2 U.mL ${ }^{-1}$ activity on 3-oxo-C 12 HSL was used. The inactive variant SsoPox 5 A8 was used the same protein quantity as SsoPox W263I. (A) Global modifications of PA14 proteome in response to lactonase treatment. The mean of normalized intensities for each condition are plotted. Only the 210 significantly changed proteins were used. The proteins are grouped according to PseudoCAP classification (http://www.pseudomonas.com). * Metabolism: Amino acid biosynthesis and metabolism/Biosynthesis of cofactors, prosthetic groups and carriers/Carbon compound catabolism/Central intermediary metabolism/Energy metabolism/Fatty acid and phospholipid metabolism/Nucleotide biosynthesis and metabolism. (B) Highlighted modifications of PA14 proteome in response to lactonase treatment. Heat map of the log 10 relative fold change mean for the six comparisons. 
which could participate in competition toward eukaryotic and prokaryotic organisms (Lesic et al., 2009; Sana et al., 2013; Jiang et al., 2014), were also detected. The abundance of HsiB3 was higher in lactonase treated samples than in control conditions especially in SsoPox W263I (fold change of +170 and +43 vs. SsoPox W263I and GcL). However, Hcp3 was only reduced with SsoPox W263I treatment (fold change of -10 vs. control).

Altogether these results evidence the large effects of AHL signal disruption using QQ lactonases on the proteome of PA14. Furthermore, these results emphasize that QQ effects between lactonases SsoPox W263I and GcL are distinct while their mixture behaves similarly to SsoPox W263I alone.

\section{DISCUSSION}

In this study, we used two different QQ lactonases, SsoPox W263I that proficiently degrades 3-oxo- $\mathrm{C}_{12}$ HSL, but has lower activity toward $\mathrm{C}_{4} \mathrm{HSL}$, and $\mathrm{GcL}$, a broad-spectrum lactonase that degrades both lactones with high proficiency. Using these two molecular tools to disrupt the QS circuits of $P$. aeruginosa, we collected phenotypic and molecular evidences that lactonase specificity toward AHLs modulates QQ outputs in P. aeruginosa.

First, the effects of both lactonases on PA14 autoinducer concentrations and QS gene expression were investigated. Despite a significant difference in $\mathrm{C}_{4}$ HSL hydrolase activity, both enzymes similarly reduced $\mathrm{C}_{4}$ HSL and 3-oxo- $\mathrm{C}_{12}$ HSL concentrations, consistently the expression levels of las and $r h l$ genes were comparable with both lactonases. A similar reduction of 3-oxo- $\mathrm{C}_{12}$ HSL and Las system is consistent with the fact that enzymes were used at similar activity levels toward this substrate. However, similar reductions of $\mathrm{C}_{4} \mathrm{HSL}$ and $\mathrm{Rhl}$ systems is more surprising as SsoPox W263I is less active than GcL against this AHL. The efficient reduction of $\mathrm{C}_{4}$ HSL observed with SsoPox W263I could originate from a slow but sufficient degradation of this AHL throughout the growth of the bacteria leading at the end of the growth to similar results than GcL. Expression of $p q s R$ was also reduced with both enzymes suggesting that interfering with AHLs affects other QS systems underlining the interconnection of the three QS systems. We also investigated several pathogenicity-related phenotypes such as pyocyanin, protease, elastase production, biofilm formation and ability to compete. We showed that the lactonase GcL, which is highly proficient against both AHLs, exhibited inhibitory activity at concentrations lower than SsoPox W263I for the production of pyocyanin, protease, and elastase. At concentrations of 0.4 and $2 \mathrm{U} \cdot \mathrm{mL}^{-1}$, these three factors were quenched by either enzymes or the combination of both enzymes, evidencing that QQ of these factors is dose-dependent. At low enzyme concentrations, pyocyanin production was increased for all lactonase treatments. This result is consistent with a previous report in which pyocyanin could be induced using a QSI antagonizing RhlR, probably by alleviating RhlR inhibition of PQS system (Welsh et al., 2015). Similarly, low lactonase concentrations could lead to reduced levels of $\mathrm{C}_{4}$ HSL that partially alleviate RhlR inhibition on PQS and lead to the induction of pyocyanin production. Pyocyanin was the only tested factor to be induced at low enzyme concentrations. Finally, the competition between PA14 and E. coli was also equally affected by any enzymatic treatment with a restoration of E. coli survival upon lactonase treatment. These results are supported by the proteomic data which showed that levels of proteins involved in phenazine synthesis and the type VI secretion system were similarly impacted by any enzyme or combination. Thereby, lactonase specificity does not impact QQ of these phenotypes which regulation may mainly rely on AHL based QS systems.

Nevertheless, several major differences arose from the different enzymatic treatments. First SsoPox W263I completely inhibited biofilm formation while cell aggregates were still observable with $G c \mathrm{~L}$ treatment, including at high enzyme concentrations. Thereby the difference in QQ efficiencies concerning biofilm formation does not solely depend on the AHL hydrolytic activity levels, but lactonase specificity plays an important role for its inhibition. Additionally, SsoPox W263I was more efficient than GcL to increase susceptibility of P. aeruginosa PA14 biofilm to $\mathrm{H}_{2} \mathrm{O}_{2}$ and antibiotics. Likewise, in the eukaryotic competition assay, only the treatment with SsoPox W263I decreased PA14 virulence and restored the growth of amoebas. Consistently with phenotypic results, a fraction of the observed variations in PA14 proteomes were largely different as a function of the lactonase substrate specificity. Specifically, distinct regulations occurred in antibiotic resistance, biofilm formation or virulence related proteins echoing alterations observed in phenotypes between lactonase treatments. Regarding QS gene expression levels, a drastic difference arose with the significant and strong reduction of pqsA expression in SsoPox W263I treated samples only. This result is consistent with proteomic observations since the levels of PqsD and PqsE, both encoded in the same operon as $p q s A$, were found less abundant in samples treated with SsoPox W263I as compared to GcL. Subsequently, we measured PQS and HHQ concentration levels in culture supernatants and showed that PQS levels were only decreased upon treatment with SsoPox W263I and that its precursor HHQ was increased upon treatment with GcL, suggesting that lactonases differentially impact QS hierarchy. Because PQS is known to contribute to virulence, biofilm and antibiotic susceptibility, variations in PQS concentrations may be involved in the observed differences between lactonaseinduced phenotypes (Häussler and Becker, 2008; Lee and Zhang, 2015; Hazan et al., 2016; Maura et al., 2016; Rampioni et al., 2016; Maura and Rahme, 2017). Thereby lactonase specificity differently impacts QS at the molecular level resulting in different phenotypic outputs of QQ.

Unexpectedly, despite exhibiting a narrower substrate specificity spectrum, the lactonase SsoPox W263I inhibited a wider range of virulence-related phenotypes in PA14 than the broad spectrum GcL. In a final set of experiments, combining both enzymes resulted in the same phenotypes, gene expression profiles and proteomes as observed with SsoPox W263I alone. The differences observed in PA14 behaviors following the applied lactonase treatment may be completely explained by AHL substrate preferences, specifically in regards to 3-oxo- $\mathrm{C}_{12}$ HSL and $\mathrm{C}_{4} \mathrm{HSL}$, of both enzymes. It can also be related to other differences in their catalytic parameters. For example, 
SsoPox W263I shows a higher affinity for 3-oxo-C 12 HSL than GcL (i.e., lower $K_{M}$ value, meaning that SsoPox W263I is able to reach its maximum rate of reaction at lower concentration of substrate than $G c \mathrm{~L}$ ), and this might modulate the balance between 3-oxo- $\mathrm{C}_{12} \mathrm{HSL}$ and $\mathrm{C}_{4} \mathrm{HSL}$ concentrations. It is also possible that some of the observed changes are due to a different, unknown activity of these enzymes since both enzymes are known to be promiscuous. Indeed, both enzymes are known to proficiently hydrolyze various $\delta$ - and $\gamma$-lactones and to exhibit other low hydrolytic activities against phosphotriesters (both enzymes) and arylesters (SsoPox W263I) (Merone et al., 2005; Hiblot et al., 2013; Bergonzi et al., 2019).

We demonstrated that the specificity of the used QQ lactonase is important to interference strategies: indeed, while both enzymes are capable of decreasing virulence factors and biofilm formation in vitro, the magnitude of inhibition and their performances in the tested systems, including in vivo, largely vary. Counterintuitively, the lactonase showing the broader activity toward AHLs did not induce the larger QQ impact in PA14. This informs us about the complexity of the interplay between the two AHL QS systems in PA14 and reveals that signal integration by the cell is likely neither linear nor additive. Nevertheless, QQ lactonases constitute promising tools to modulate bacterial communications and associated behaviors including host-bacteria and bacteria-bacteria interactions in complex ecosystems. Lactonases with various specificities should be further assayed on a wider selection of $P$. aeruginosa strains as its QS network is known to vary from one strain to another and to evolve in contact with hosts and other bacteria (Chugani et al., 2012; Feltner et al., 2016; Kostylev et al., 2019; Mahan et al., 2020). Even though QS regulation varies depending on growth conditions and strains, we provide evidence that more than the dose, the choice of enzyme is crucial to maximize QQ strategies.

\section{MATERIALS AND METHODS}

\section{Bacterial Strains}

For enzyme production, Escherichia coli BL21 (DE) 3 -carrying plasmids pGro7/GroEL for chaperones and pET22b with either SsoPox W263I, SsoPox 5A8 (V27G/P67Q/L72C/Y97S/ Y99A/T177D/R223L/L226Q/L228M/W263H) or N-terminal strep tagged GcL wild type were used (Bergonzi et al., 2016; Guendouze et al., 2017). E. coli E. cloni ${ }^{\circledR} 10 \mathrm{G}$ transformed with the plasmid pGEM $^{\circledR}-3 Z f(+)$ (constitutive expression of lac $Z$ alpha peptide) was used in the virulence assay. For AHL measurement, the biosensor strains Pseudomonas putida KS35 and Chromobacterium violaceum CV026 were used (McClean et al., 1997; Steidle et al., 2001). For all the phenotypic and proteomic studies, Pseudomonas aeruginosa PA14 (UCBPP-14) was used.

\section{Enzyme Production and Purification}

SsoPox W263I and 5A8 were produced as previously described (Guendouze et al., 2017). Overnight precultures were incubated at $37^{\circ} \mathrm{C}$ in Luria Bertani (LB) medium (10 g.L $\mathrm{L}^{-1} \mathrm{NaCl}$, 10 g. $\mathrm{L}^{-1}$ tryptone, and 5 g.L $\mathrm{L}^{-1}$ yeast extract) complemented with chloramphenicol (34 $\left.\mu \mathrm{g} \cdot \mathrm{mL}^{-1}\right)$ and ampicillin $\left(100 \mu \mathrm{g} \cdot \mathrm{mL}^{-1}\right)$. Then, cultures in ZYP-5052 medium complemented with the same antibiotics were inoculated and incubated at $37^{\circ} \mathrm{C}$ until optical density at $600 \mathrm{~nm}$ reached $0.8-1$ (Studier, 2005). At this state, $\mathrm{CoCl}_{2}$ and $\mathrm{L}$-arabinose were added at a final concentration of $0.2 \mathrm{mM}$ and $0.2 \%(\mathrm{w} / \mathrm{v})$. Cultures were further incubated at $23^{\circ} \mathrm{C}$ for another $20 \mathrm{~h}$. Afterward, cells were pelleted down by centrifugation $\left(4,400 \times g, 4^{\circ} \mathrm{C}, 20 \mathrm{~min}\right)$ and resuspended in HEPES lysis buffer (50 mM HEPES, $150 \mathrm{mM}$ $\mathrm{NaCl}, 0.25 \mathrm{mg} \cdot \mathrm{mL}^{-1}$ lysozyme, $0.1 \mathrm{mM}$ phenylmethylsulfonyl fluoride (PMSF), $10 \mathrm{mg} \cdot \mathrm{mL}^{-1} \mathrm{DNaseI}$ and $\mathrm{pH}$ 8.0). The cells were stored overnight at $-80^{\circ} \mathrm{C}$. The next day, cells were thawed and sonicated three times for $30 \mathrm{~s}$ with an amplitude of 45\% (QSonica sonicator Q700). Cell debris was pelleted down by centrifugation $\left(12,000 \times g, 4^{\circ} \mathrm{C}, 30 \mathrm{~min}\right)$ and discarded. The supernatant was heated at $80^{\circ} \mathrm{C}$ over $30 \mathrm{~min}$ to precipitate E. coli proteins which were removed afterward by centrifugation $\left(12,000 \times g, 4^{\circ} \mathrm{C}\right.$, $15 \mathrm{~min})$. The remaining proteins were incubated overnight at $4^{\circ} \mathrm{C}$ in $75 \%$ ammonium sulfate in order to precipitate and concentrate SsoPox. After resuspension in HEPES buffer (50 mM HEPES, $150 \mathrm{mM} \mathrm{NaCl}$ and $\mathrm{pH} 8.0$ ), ammonium sulfate was eliminated via desalting (HiPrep 26/10 desalting, GE Healthcare; ÄKTA Avant). The resulting fractions were pooled and concentrated with $10 \mathrm{kDA}$ centricon (Millipore). The proteins were then loaded onto a size exclusion chromatography column (HiLoad 16/600 Superdex ${ }^{\mathrm{TM}} 75 \mathrm{pg}$, GE Healthcare; ÄKTA Avant) and were eluted in HEPES buffer.

For $G c \mathrm{~L}$, cultures were realized in the same conditions, but cells were resuspended in Tris- $\mathrm{HCl}$ lysis buffer $(50 \mathrm{mM}$ Tris$\mathrm{HCl}, 300 \mathrm{mM} \mathrm{NaCl}, 0.25 \mathrm{mg} \cdot \mathrm{mL}^{-1}$ lysozyme, $0.1 \mathrm{mM}$ PMSF and $10 \mathrm{mg} \cdot \mathrm{mL}^{-1} \mathrm{DNaseI}$ and $\mathrm{pH}$ 8.0). After being stored overnight at $-80^{\circ} \mathrm{C}$, resuspended cells were thawed and sonicated twice for $30 \mathrm{~s}$ with an amplitude of $45 \%$. Cell debris was pelleted down by centrifugation $\left(12,000 \times g, 4^{\circ} \mathrm{C}, 30 \mathrm{~min}\right)$. The crude extract was then loaded onto a Strep-tag column (5 mL StrepTrap HP, GE Healthcare; ÄKTA Avant). The elution was performed in Tris- $\mathrm{HCl}$ buffer (50 mM Tris- $\mathrm{HCl}, 300 \mathrm{mM} \mathrm{NaCl}$ and $\mathrm{pH} 8.0$ ) complemented with $2.5 \mathrm{mM}$ of desthiobiotin (Sigma Aldrich).

After purification on chromatography column, the GcL or SsoPox containing fractions were pooled and concentrated with $30 \mathrm{kDa}$ centricon (Millipore). The purity of each protein was checked by $12.5 \%$ SDS-PAGE separation and the concentration was measured using a NanoDrop 2000 spectrophotometer (Thermo Scientific).

\section{Lactonase Activity Measurement}

The activity was measured on (L)-3-oxo- $\mathrm{C}_{12}$ and (L)- $\mathrm{C}_{4}$ HSL at ambient temperature using a colorimetric $\mathrm{pH}$ based assay (Bergonzi et al., 2016). Briefly, lactone ring hydrolysis leads to acidification of the solution which is followed by the absorbance modification of a $\mathrm{pH}$ indicator (cresol). For kinetic parameters, the degradation of lactones at different concentrations by each enzyme in a cresol buffered solution $(1.25 \mathrm{mM}$ Bicine, $150 \mathrm{mM}$ $\mathrm{NaCl}, 0.2 \mathrm{mM} \mathrm{CoCl}_{2}, 0.25 \mathrm{mM}$ cresol purple, $3.5 \%$ or a minimum of $1.5 \%$ DMSO for respectively 3 -oxo- $\mathrm{C}_{12}$ and $\mathrm{C}_{4} \mathrm{HSL}$, and $\mathrm{pH}$ 8.3) was followed in $200 \mu \mathrm{L}$ at $577 \mathrm{~nm}$ using a plate reader (SynergyHT, BioTek). $5 \mu \mathrm{g}$ of SsoPox W263I and 1.6 $\mu \mathrm{g}$ GcL 
were used on 3-oxo-C 12 HSL and $50 \mu \mathrm{g}$ of SsoPox W263I and $1.6 \mu \mathrm{g}$ of $\mathrm{GcL}$ on $\mathrm{C}_{4}$ HSL. For specific activity determination, one saturating concentration of AHL was tested ( $8 \mathrm{mM}$ for $\mathrm{C}_{4}$ HSL and $1 \mathrm{mM}$ for 3-oxo- $\mathrm{C}_{12} \mathrm{HSL}$ ). One enzymatic unit (U) corresponds to $1 \mu \mathrm{mol}$ of substrate hydrolyzed per minute. For SsoPox 5A8, up to $500 \mu \mathrm{g}$ of protein were used and it proved active toward neither $\mathrm{C}_{4}$ nor 3-oxo- $\mathrm{C}_{12}$ HSL.

\section{Culture Media and Conditions}

Selected medium and culture conditions were adapted from Welsh and Blackwell (2016). Briefly, P. aeruginosa PA14 was precultivated in $\mathrm{LB}$ in a $25 \mathrm{~cm}^{2}$ culture flask (Corning) and incubated over $5-6 \mathrm{~h}$ at $37^{\circ} \mathrm{C}$ with a $300 \mathrm{rpm}$ agitation (Titramax 3000 , Heidolph) to then inoculate cultures at $1 / 1,000$. Cultures were realized in MOPS minimal medium (50 mM MOPS, $4 \mathrm{mM}$ Tricine, $50 \mathrm{mM} \mathrm{NaCl}, 1 \mathrm{mM} \mathrm{K} \mathrm{SO}_{4}, 50 \mu \mathrm{M} \mathrm{MgCl}_{2}, 10 \mu \mathrm{M}$ $\mathrm{CaCl}_{2}, 0.3 \mu \mathrm{M}\left(\mathrm{NH}_{4}\right)_{6} \mathrm{Mo}_{7} \mathrm{O}_{24}, 40 \mu \mathrm{M} \mathrm{H}_{3} \mathrm{BO}_{3}, 3 \mu \mathrm{M} \mathrm{Co}(\mathrm{OAc})_{2}$, $1 \mu \mathrm{M} \mathrm{CuSO}_{4}, 8 \mu \mathrm{M} \mathrm{MnSO}_{4}, 1 \mu \mathrm{M} \mathrm{ZnSO}_{4}, \mathrm{pH} 7$, filter sterilized) complemented with nitrogen $\left(15 \mathrm{mM} \mathrm{NH}_{4} \mathrm{Cl}\right)$, iron $(5 \mu \mathrm{M}$ $\left.\mathrm{Fe}_{2} \mathrm{SO}_{4}\right)$, phosphate $\left(4 \mathrm{mM} \mathrm{K} \mathrm{K}_{2} \mathrm{HPO}_{4}\right)$ and carbon $(25 \mathrm{mM}$ glutamate) source. Cultures received either SsoPox W263I, GcL or a mixture of both enzymes $(50 \% / 50 \%)$ to have the same activity (U.mL $\mathrm{mL}^{-1}$ ) on 3 -oxo-C 12 HSL in all conditions. The inactive variant $S$ soPox $5 \mathrm{~A} 8$ was added in a quantity equivalent to SsoPox W263I.

For growth measurement, cells were grown over $26 \mathrm{~h}$ at $37^{\circ} \mathrm{C}$ and $300 \mathrm{rpm}$ agitation. Cell density was estimated by measuring the optical density at $600 \mathrm{~nm}$ with a plate reader (SynergyHT, BioTek) and $200 \mu \mathrm{L}$ of planktonic cells.

\section{AHL Extraction and Measurement}

Acyl-homoserine lactone extraction was performed using a modified method of ethyl acetate liquid-liquid extraction (Elasri et al., 2001). From $1 \mathrm{~mL}$ of MOPS bacterial culture, cells were removed by centrifugation $(10,000 \times g, 5 \mathrm{~min})$ and the supernatant was extracted once with ethyl acetate $(1: 1 \mathrm{v} / \mathrm{v})$. The organic upper phase was evaporated to dryness, and the residues were resuspended into $15 \mu \mathrm{L}$ of DMSO. As blank, sterile MOPS medium was extracted the same way.

Acyl-homoserine lactones were quantified in the extract using two reporter strains: P. putida KS35 and C. violaceum CV026. $P$. putida KS35 harbored an integrated transposon carrying a lasR gene controlled by a lac promoter and a $g f p$ gene fused to las $\mathrm{B}$ promoter which can be activated by LasR binding 3oxo- $\mathrm{C}_{12}$ HSL (Steidle et al., 2001). C. violaceum CV026 do not produce AHLs ( $c v I$ inactivated) but able to detect short-chain AHLs (McClean et al., 1997).

For 3-oxo-C 12 HSL detection, P. putida KS35 was precultivated overnight in LB (supplemented with $50 \mu \mathrm{g} / \mathrm{mL}$ kanamycin) at $30^{\circ} \mathrm{C}$ and then diluted to $1 / 10$ in $1 \mathrm{~mL}$ of fresh $\mathrm{LB}$ with $5 \mu \mathrm{L}$ of extract. After $8 \mathrm{~h}$ of culture at $30^{\circ} \mathrm{C}$, the fluorescence was measured using a plate reader (SynergyHT, BioTek) with an excitation wavelength of $485 \mathrm{~nm}$ and emission detection at $528 \mathrm{~nm}$. For $\mathrm{C}_{4} \mathrm{HSL}$, C. violaceum CV026 was precultivated overnight in $\mathrm{LB}$ at $30^{\circ} \mathrm{C}$ and then diluted to $1 / 1,000$ in $1 \mathrm{~mL}$ of fresh $\mathrm{LB}$ with $10 \mu \mathrm{L}$ of extract. After $24 \mathrm{~h}$ of culture at $30^{\circ} \mathrm{C}$, the violacein was quantified using a method based on ethyl acetate extraction (Collins et al., 1980). Briefly, $0.5 \mathrm{~mL}$ of cell culture was vigorously mixed with ethyl acetate $(1: 1 \mathrm{v} / \mathrm{v})$ and then $200 \mu \mathrm{L}$ of the organic upper phase were transferred into a quartz 96 well plate and the OD at $565 \mathrm{~nm}$ was measured. Results for each AHL measurement were plotted after background noise removal.

\section{PQS and HHQ Extraction and Measurement}

Pseudomonas quinolone signal and HHQ were extracted, as previously described for AHLs, from $1 \mathrm{~mL}$ of culture medium with equal volume of ethyl acetate. As blank, sterile MOPS medium was used. After evaporation of the organic phase, the residues were resuspended into $100 \mu \mathrm{L}$ of HPLC-grade methanol.

For screening and measurement, liquid chromatography coupled to mass spectrometry (LC-MS) was used. Water, methanol and formic acid were ULC-MS grade (Biosolve, Dieuze). Analysis was performed with an Acquity I-Class UPLC chromatography system connected to a Vion IMS Qtof ion mobility-quadrupole-time of flight mass spectrometer (Waters). Samples were maintained at $4^{\circ} \mathrm{C}$ and randomly injected $(5 \mu \mathrm{L})$ into a reverse phase column maintained at $35^{\circ} \mathrm{C}$ (Acquity $\mathrm{BEH}$ C18 $1.7 \mu \mathrm{m} 2.1 \times 50 \mathrm{~mm}$, Waters). Mobile phase flow rate was $0.5 \mathrm{~mL} \cdot \mathrm{min}^{-1}$ and a composition gradient was set as follows: using water (A) and methanol (B) each containing $0.1 \%$ formic acid: 30 to $95 \%$ of $\mathrm{B}$ ( $2 \mathrm{~min}), 95 \%$ of $\mathrm{B}$ ( $1 \mathrm{~min})$, initial composition (1 min). Compounds were ionized in the positive mode with a Zspray electrospray ion source: capillary/cone $1.5 \mathrm{kV} / 20 \mathrm{~V}$, source/desolvation $120 / 250^{\circ} \mathrm{C}$. Ions were monitored using a High Definition MS(E) data independent acquisition method combining a traveling wave ion mobility survey and a tandem MS monitoring (50-1000 m/z, 0.1 s scan time, 6 and 20-30 eV for low and high energy alternate scans, automatic lockmass correction using Leucine Enkephalin at $\mathrm{m} / \mathrm{z}$ 556.2766). The spectrometer was calibrated beforehand (Major Mix, Waters) to enable Collision Cross Section (CCS) and $\mathrm{m} / \mathrm{z}$ values measurements. Ion components (retention time, ion mobility drift time and parents/fragments $\mathrm{m} / \mathrm{z}$ values) were collected from raw data using the UNIFI software (version 1.9.3, Waters). Structures were targeted as follows: 0.2 min retention time window, 2\% CCS tolerance (experimental CCS values were $165 / 167 \AA^{2}$ for HHQ/PQS), $3 \mathrm{ppm} \mathrm{m} / \mathrm{z}$ tolerance on parent $[\mathrm{M}+\mathrm{H}]+$ adducts $(\mathrm{m} / \mathrm{z}$ 244.1696/260.1645 for HHQ/PQS) and $10 \mathrm{mDa} \mathrm{m} / \mathrm{z}$ tolerance on predicted fragments (including $\mathrm{m} / \mathrm{z}$ 159.0679/175.06205 for HHQ/PQS). For calibration, HHQ/PQS stock solutions were prepared in methanol from pure standards (>96\%; Sigma Aldrich). Culture medium was spiked with both compounds at concentrations ranging from $2 \mathrm{nM}$ to $20 \mu \mathrm{M}$ for HHQ and from $4 \mathrm{nM}$ to $40 \mu \mathrm{M}$ for PQS, every 10 -fold. The molecules were extracted in the same conditions as previously described and the calibration curve was fitted point to point in order to estimate the concentrations of HHQ/PQS compounds ( $<15 \%$ deviation on controls).

\section{RNA Extraction and QS Gene Expression Measurement}

From $200 \mu \mathrm{L}$ of culture cells pellet, RNA was extracted and purified with PureLink ${ }^{\mathrm{TM}}$ RNA Mini Kit (Invitrogen) and 
residual DNA were digested with TURBO DNA-Free ${ }^{\mathrm{TM}}$ kit (Invitrogen). Then cDNA was synthesized using TaqMan ${ }^{\mathrm{TM}}$ Reverse Transcription Reagents (Applied Biosystems) and provided random hexamers. Eventually, qPCR was realized using LightCycler $^{\circledR} 480$ SYBR Green I Master (Roche), and a CFX96 Touch $^{\text {TM }}$ Real Time PCR Detection System (BioRad). Primers used are indicated in Supplementary Table S1. The resulting data for each gene were normalized using housekeeping gene $r e c A$ expression and analyzed using the $2^{-\Delta \mathrm{Ct}}$ method (Schmittgen and Livak, 2008). The results were plotted as relative expression level by dividing each $2^{-\Delta \mathrm{Ct}}$ values by the mean of the control without added protein.

\section{Virulence Factors Measurement}

Pyocyanin was extracted by mixing $250 \mu \mathrm{L}$ of chloroform in $500 \mu \mathrm{L}$ of cell-free supernatant. After centrifugation at $10,000 \times g$ for $1 \mathrm{~min}, 200 \mu \mathrm{L}$ of the lower chloroform phase were transferred into a quartz 96 well plate. As blank, $200 \mu \mathrm{L}$ of chloroform were used. The absorbance was measured at $690 \mathrm{~nm}$ (Price-Whelan et al., 2007). Results for each condition were plotted after blank absorbance removal.

Protease activity was measured by using azocasein (Sigma Aldrich) degradation assay (Chessa et al., 2000). Briefly, $25 \mu \mathrm{L}$ of cell-free supernatant were mixed with $675 \mu \mathrm{L}$ of phosphate saline buffer $\mathrm{pH} 7.0$ and $50 \mu \mathrm{L}$ of azocasein solution $\left(30 \mathrm{mg} \cdot \mathrm{mL}^{-1}\right.$ in water). After $2 \mathrm{~h}$ at $37^{\circ} \mathrm{C}$ with agitation (300 rpm), $125 \mu \mathrm{L}$ of $20 \%(\mathrm{w} / \mathrm{v})$ trichloroacetic acid were added. Then, undegraded azocasein was pelleted down by centrifugation $(10,000 \times g$, $5 \mathrm{~min}$ ). Afterward, $200 \mu \mathrm{L}$ of supernatant were used to measure the optical density at $366 \mathrm{~nm}$. As blank, an equivalent volume of sterile MOPS medium was used. Results for each condition were plotted after blank absorbance removal.

Elastase B activity was measured by using elastin-Congo red conjugate (Sigma Aldrich) degradation assay (Smith et al., 2003). In a 96 well plastic plate (Greiner), $50 \mu \mathrm{L}$ of cell-free supernatant were mixed with $150 \mu \mathrm{L}$ of elastin-Congo red solution (5 mg.mL $\mathrm{mL}^{-1}$ in $10 \mathrm{mM}$ Tris- $\mathrm{HCl}$ and $1 \mathrm{mM} \mathrm{CaCl}_{2}$ buffer at $\mathrm{pH} 7.2$ ). After $24 \mathrm{~h}$ incubation at $37^{\circ} \mathrm{C}$ with agitation (300 rpm), the plate was left to rest for $10 \mathrm{~min}$ at ambient temperature in order to pellet undigested elastin-Congo red. Afterward, $100 \mu \mathrm{L}$ of the reaction were carefully transferred into an empty well and then absorbance was measured at $490 \mathrm{~nm}$. As blank, an equivalent volume of sterile MOPS medium was used. Results for each condition were plotted after blank absorbance removal.

\section{Biofilm Formation Measurement}

Biofilm was measured using crystal violet (Sigma Aldrich) biomass staining (Hoffman et al., 2005). After culture in 12 well plates (Nunc ${ }^{\mathrm{TM}}$, Thermo Scientific), planktonic cells were carefully removed by pipetting. Wells were washed with $3 \mathrm{~mL}$ of phosphate buffered saline (PBS) solution (Biomérieux), dried at $37^{\circ} \mathrm{C}$ and stained with $3 \mathrm{~mL}$ of $0.05 \%$ (w/v) crystal violet solution. After removing crystal violet, wells were washed with $4 \mathrm{~mL}$ of PBS and fixed crystal violet was dissolved with $3 \mathrm{~mL}$ of pure ethanol. Using $200 \mu \mathrm{L}$, absorbance was measured at $595 \mathrm{~nm}$.
As blank, sterile MOPS medium was used in the same culture conditions. Results for each condition were plotted after blank absorbance removal.

\section{Antimicrobial Sensitivity Assay}

The effect of tobramycin, gentamicin and hydrogen peroxide on PA14 was evaluated using the $\mathrm{MBEC}^{\mathrm{TM}}$ assay (Innovotech) (Harrison et al., 2010). As previously described, PA14 was grown in $180 \mu \mathrm{L}$ MOPS medium in the 96 well plate of the $\mathrm{MBEC}^{\mathrm{TM}}$ assay device for $24 \mathrm{~h}$ at $37^{\circ} \mathrm{C}$ under orbital agitation (110 rpm). Afterward, the lid was transferred, first to a 96 well plate containing $190 \mu \mathrm{L}$ of fresh non-complemented MOPS medium to wash the planktonic cells and then transferred to another plate containing antimicrobial agents. Tobramycin and gentamicin were used at concentrations ranging from 0 to $20 \mu \mathrm{g} \cdot \mathrm{mL}^{-1}$ and $\mathrm{H}_{2} \mathrm{O}_{2}$ from 0 to $500 \mathrm{mM}$. PA14 was exposed under agitation (110 rpm) for $1.5 \mathrm{~h}$ and $3 \mathrm{~h}$ to $\mathrm{H}_{2} \mathrm{O}_{2}$ and antibiotics, respectively. The cells were washed in $200 \mu \mathrm{L}$ of non-complemented MOPS medium and then transferred into $200 \mu \mathrm{L}$ of recovery LB (LB supplemented with 20.0 g.L. $\mathrm{L}^{-1}$ saponin and 10.0 g.L $\mathrm{L}^{-1}$ Tween80). After $1 \mathrm{~h}$, cells were diluted in non-complemented MOPS medium and plated on LB agar. CFU were counted after 3 days growth at $20^{\circ} \mathrm{C}$.

\section{Competition Assay With E. coli}

Competition between $P$. aeruginosa PA14 and E. coli was evaluated using a modified protocol from Allsopp et al. (Allsopp et al., 2017). The E. coli strain was cultivated in LB with $100 \mu \mathrm{g} \cdot \mathrm{mL}^{-1}$ of ampicillin in a $25 \mathrm{~cm}^{2}$ culture flask and incubated over $5-6 \mathrm{~h}$ at $37^{\circ} \mathrm{C}$ with a $300 \mathrm{rpm}$ agitation to inoculate LB/ampicillin cultures at 1/1,000. After $20 \mathrm{~h}$ in 12 well plate, E. coli and MOPS cultivated PA14 were harvested from $1.2 \mathrm{~mL}$ of culture by centrifugation at $10,000 \times g$ for $5 \mathrm{~min}$. The pelleted cells were resuspended into $1.2 \mathrm{~mL}$ of PBS and $200 \mu \mathrm{L}$ were used to evaluate cell density at $600 \mathrm{~nm}$. The remaining $1 \mathrm{~mL}$ was centrifuged again, and the cells were resuspended in adequate volume of PBS in order to reach a final OD $600 \mathrm{~nm}$ of 1 in all samples. E. coli was mixed with PA14 or PBS (control) at a volume ratio of 1:5 (corresponding to a cell ratio of approximately $1: 10$ ). Then, $20 \mu \mathrm{L}$ was spotted onto $0.22 \mu \mathrm{m}$ pore size hydrophilic PDVF membrane (Durapore ${ }^{\circledR}$ GVWP01300, Millipore) resting on a $1.5 \%$ agarose plate. After incubation for $24 \mathrm{~h}$ at $37^{\circ} \mathrm{C}$, cells were recovered by washing the membrane with $200 \mu \mathrm{L}$ of PBS. Before and after the incubation, cell counts were realized with serial dilutions in PBS plated on LB agar plate complemented with $80 \mu \mathrm{g} . \mathrm{mL}^{-1}$ of 5-bromo-4-chloro3-indolyl-beta-D-galactopyranoside.

\section{Virulence Assay Toward Amoeba}

The virulence assay using amoeba was adapted from Fenner et al. (2006) and Mion et al. (2019). Acanthamoeba polyphaga Linc AP1 was routinely cultivated in peptone yeast extract glucose [20 g. $\mathrm{L}^{-1}$ proteose peptone, 2 g.L $\mathrm{L}^{-1}$ yeast extract, $0.1 \mathrm{M}$ glucose, $4 \mathrm{mM} \mathrm{MgSO}_{4}, 0.53 \mathrm{mM} \mathrm{CaCl}_{2}, 3.4 \mathrm{mM}$ sodium citrate, $50 \mu \mathrm{M}$ $\left(\mathrm{NH}_{4}\right)_{2} \mathrm{Fe}\left(\mathrm{SO}_{4}\right)_{2}, 2.5 \mathrm{mM} \mathrm{KH}_{2} \mathrm{PO}_{4}, 1.3 \mathrm{mM} \mathrm{Na}_{2} \mathrm{HPO}_{4}, \mathrm{pH}$ 6.8] medium (Fenner et al., 2006). After 2-3 days of cultivation at $28^{\circ} \mathrm{C}$, the cells were pelleted down at $750 \mathrm{~g}$ and resuspended 
in Page's amoeba saline (PAS) buffer (2 mM NaCl, $16 \mu \mathrm{M}$ $\mathrm{MgSO}_{4}, 27 \mu \mathrm{M} \mathrm{CaCl}_{2}, 0.53 \mathrm{mM} \mathrm{Na} \mathrm{HPO}_{4}, 1 \mathrm{mM} \mathrm{KH} \mathrm{PO}_{4}, \mathrm{pH}$ 6.9). The volume was adjusted to obtain a $10^{5}$ cells. $\mu \mathrm{L}^{-1}$ final concentration. As for the bacterial growth, after culture in 6 well plates (Nunc ${ }^{\mathrm{TM}}$, Thermo Scientific), $3 \mathrm{~mL}$ of bacterial culture were pelleted down and resuspended in a minimum of $1 \mathrm{~mL}$ of PAS buffer. Depending on their concentration in suspension, the buffer volume was adjusted to have the same concentration of bacteria in each condition. Then a PAS agar plate was flooded with $1 \mathrm{~mL}$ of bacterial suspension. After drying at ambient temperature, $5 \mu \mathrm{L}$ of $A$. polyphaga were spotted at the center and left to dry. Afterward, the plate was incubated at $30^{\circ} \mathrm{C}$ over 7 days. Each day, amoeba propagation was followed by directly measuring the central spot with a ruler. The results were plotted for each condition from day 0 to 7 .

\section{Protein Extraction}

Cells were harvested by centrifugation $(10,000 \times g, 5 \mathrm{~min})$ and washed with $2 \mathrm{~mL}$ of PBS and centrifuged again $(10,000 \times g$, $5 \mathrm{~min}$ ). Pellets were resuspended in $100 \mu \mathrm{L}$ of UTSTS buffer [8 M Urea, $2 \mathrm{M}$ Thiourea, $100 \mathrm{mM} \mathrm{NaCl}, 25 \mathrm{mM}$ Tris- $\mathrm{HCl}$, pH 8.2 and protease inhibitor (complete, Roche)] and sonicated on ice for $30 \mathrm{~s}$ with an amplitude of $15 \%$ (Vibra cells) until it became clear. Cell debris was removed by centrifugation $(16,000 \times g, 20 \mathrm{~min})$ and the supernatant was carefully transferred into a dialysis cassette (Slides Alyzer dialysis cassette $2 \mathrm{~K}$ MWCO, Thermo scientific). The cassette was incubated for $4 \mathrm{~h}$ in $2 \mathrm{~L}$ with Urea/Ambic buffer (1 M Urea, $50 \mathrm{mM}$ ammonium bicarbonate, $\mathrm{pH}$ 7.4) and overnight in $2 \mathrm{~L}$ of fresh Urea/Ambic buffer. Protein quantity was estimated with Braford assay (BioRad) and $50 \mu \mathrm{g}$ of proteins were mixed to Urea/Ambic buffer to a final volume of $50 \mu \mathrm{L} .1 \mu \mathrm{L}$ of $0.5 \mathrm{M}$ dithiothreitol in Urea/Ambic buffer was added for the reduction of disulfide bonds and the reaction was conducted over $1 \mathrm{~h}$ at $37^{\circ} \mathrm{C}$. For alkylation, $2 \mu \mathrm{L}$ of $0.5 \mathrm{M}$ iodoacetamide in Urea/Ambic buffer were added and let to react over $1 \mathrm{~h}$ protected from light. Afterward, $\mathrm{pH}$ was checked to be above 7 . Protein digestion was performed by adding $2 \mu \mathrm{L}$ of $1 \mu \mathrm{g} \cdot \mathrm{mL}^{-1}$ trypsin (Agilent) and samples were incubated overnight at $37^{\circ} \mathrm{C}$. Digestion efficiency was checked on $10 \%$ SDS-PAGE gel. Finally, a detergent removal spin column (Pierce ${ }^{\mathrm{TM}}$, Thermo Fisher) and a C18 spin column (Pierce ${ }^{\mathrm{TM}}$, Thermo Fisher) were used to clean the samples.

\section{Label-Free Quantitative Nano-LC-MS/MS Proteomics Analysis}

In a first step, protein digests were separated by Ultra Performance liquid chromatography (UPLC) using the NanoAcquity UPLC System (Waters) connected to a Synapt G2Si Q-TOF ion mobility hybrid mass spectrometer (Waters). The chromatographic system was used in 1D configuration with an analytical column (ACQUITY UPLC M-Class Trap Column Reversed-Phase $1.7 \mu \mathrm{m}$ spherical Hybrid, CSH, $75 \mu \mathrm{m} \times 150 \mathrm{~mm}$, Waters) after a trapping column (ACQUITY UPLC M-Class Trap Column Reversed-Phase $5 \mu \mathrm{m}$ spherical silica, $180 \mu \mathrm{m} \times 20 \mathrm{~mm}$, Waters). Eluted peptides were separated using a $100 \mathrm{~min}$ gradient $\left(300 \mathrm{~nL} \cdot \mathrm{min}^{-1} ; 0.5\right.$ to $40 \%$ acetonitrile- $0.1 \%$ formic acid). Data-independent MS/MS analysis was performed with the ion mobility feature (HDMSe method). The ion source parameters were: capillary voltage $3 \mathrm{kV}$, sampling cone voltage $40 \mathrm{~V}$, ion source temperature $90^{\circ} \mathrm{C}$, cone gas flow $50 \mathrm{~L} . \mathrm{h}^{-1}$. Transfer collision low energy was set to $5 \mathrm{~V}$, trap collision low energy was set to $4 \mathrm{~V}$. The high energy ramp was applied from $4 \mathrm{~V}$ to $5 \mathrm{~V}$ for the trap collision and from $19 \mathrm{~V}$ to $45 \mathrm{~V}$ for the transfer collision enabling fragmentation of the ions after the ion mobility cell and before the time-of-flight (TOF) MS. On-column sample load was $800 \mathrm{ng}$ ( $2 \mu \mathrm{L}$ injected). Each sample was injected in duplicate.

\section{Proteomic Data Processing and Analysis}

The acquired files were imported into Progenesis QI software Version 2.0 (Non-linear Dynamics, Newcastle, United Kingdom) for label-free quantification analysis. The data were aligned automatically and normalized. Processing parameters were 150 counts for the low energy threshold, 30 counts for the elevated energy threshold. The database used to identify peptides contains the protein sequences of Pseudomonas aeruginosa PA14 (TrembL, 25/04/2017, 5,886 sequences). Search tolerance parameters were: peptide and fragment tolerance, $15 \mathrm{ppm}$, FDR $<1 \%$; Minimum Ion matching requirements were three fragments per peptide, seven fragments per protein and two peptides per protein. The enzyme specificity was trypsin allowing 1 missed cleavage, the accepted modifications were carbamidomethyl of cysteine (fixed), oxidation of methionine (variable), carbamyl of lysine and N-terminal (variable), deamidation (variable) of asparagine and glutamine. The protein normalization was performed according to the relative quantitation using non-conflicting peptides. To determine the significance of changes between samples, a significant ANOVA $\left(p_{\text {value }}<0.05\right)$ and a fold change superior to 2 were used as the thresholds to define differently expressed protein. The mass spectrometry proteomics data have been deposited to the ProteomeXchange Consortium via the PRIDE (Perez-Riverol et al., 2019) partner repository with the dataset identifier PXD017421.

The principal component analysis (PCA) was performed on normalized data using SIMCA 14. The data were Pareto scaled, autofitted for principal components and the Hotelling's $T^{2}$ was used to assess the possible presence of outlier.

For the heat map, the logarithm with base $10\left(\log _{10}\right)$ of the fold change was calculated. According to the reference condition, either $\log _{10}$ (higher expressed) or $-\log _{10}$ (lower expressed) was used in the representation. Non-significant fold changes $\left(p_{\text {value }} \geq 0.05\right.$ and/or fold change $\left.<2\right)$ were considered to have a value equal to 1 and were represented by a zero on the heat map.

\section{Statistical Analyses}

For virulence factors, biofilm, competition assay with E. coli and QS gene expression measurement data, statistical analyses were performed using GraphPad Prism 7. The significance level $(\alpha)$, or the probability of committing a type I error, was set at 0.05 . For all these data, normality distribution was checked with the D’Agostino and Pearson omnibus normality test. 
For virulence factors and biofilm, statistical analyses were performed on raw optical density data (without blank removal). A two-way ANOVA was performed according to enzyme treatment and concentration. Then when ANOVA $p_{\text {value }}$ was inferior to 0.05 , the Holm-Sidak's multiple comparisons test was used to assess the difference between SsoPox 5A8 (inactive) and SsoPox W263I, GcL or SsoPox W263I + GcL; SsoPox W263I and $G c \mathrm{~L}$ or SsoPox W263I + GcL; GcL and SsoPox W263I + GcL for each concentration.

For the QS gene expression, statistical analyses were performed on $2^{-\Delta \mathrm{Ct}}$ (Schmittgen and Livak, 2008). For the competition assay and QS gene expression, a one-way ANOVA was used and if the ANOVA $p_{\text {value }}$ was inferior to 0.05 , the Sidak's multiple comparison test was used to assess the difference between: without protein and SsoPox 5A8 (inactive); SsoPox 5A8 (inactive) and SsoPox W263I, GcL or SsoPox W263I + GcL; SsoPox W263I and GcL or SsoPox W263I + GcL; GcL and SsoPox W263I + GcL.

\section{DATA AVAILABILITY STATEMENT}

The datasets generated for this study can be found in the ProteomeXchange via the PRIDE database, accession PXD017421.

\section{AUTHOR CONTRIBUTIONS}

BR, LP, ME, DD, and EC designed the research. BR, LP, NA, and $\mathrm{PD}$ performed the research. BR, LP, and DD analyzed the data.

\section{REFERENCES}

Aendekerk, S. (2005). The MexGHI-OpmD multidrug efflux pump controls growth, antibiotic susceptibility and virulence in Pseudomonas aeruginosa via 4-quinolone-dependent cell-to-cell communication. Microbiology 151, 11131125. doi: 10.1099/mic.0.27631-0

Allsopp, L. P., Wood, T. E., Howard, S. A., Maggiorelli, F., Nolan, L. M., Wettstadt, S., et al. (2017). RsmA and AmrZ orchestrate the assembly of all three type VI secretion systems in Pseudomonas aeruginosa. Proc. Natl. Acad. Sci. U.S.A. 114, 7707-7712. doi: 10.1073/pnas.1700286114

Balasubramanian, D., Schneper, L., Kumari, H., and Mathee, K. (2013). A dynamic and intricate regulatory network determines Pseudomonas aeruginosa virulence. Nucleic Acids Res. 41, 1-20. doi: 10.1093/nar/gks1039

Bergonzi, C., Schwab, M., and Elias, M. (2016). The quorum-quenching lactonase from Geobacillus caldoxylosilyticus: purification, characterization, crystallization and crystallographic analysis. Acta Crystallogr. Sect. F Struct. Biol. Commun. 72, 681-686. doi: 10.1107/S2053230X16011821

Bergonzi, C., Schwab, M., Naik, T., and Elias, M. (2019). The structural determinants accounting for the broad substrate specificity of the quorum quenching lactonase GcL. ChemBioChem 20, 1848-1855. doi: 10.1002/cbic. 201900024

Borlee, B. R., Goldman, A. D., Murakami, K., Samudrala, R., Wozniak, D. J., and Parsek, M. R. (2010). Pseudomonas aeruginosa uses a cyclic-di-GMPregulated adhesin to reinforce the biofilm extracellular matrix. Mol. Microbiol. 75, 827-842. doi: 10.1111/j.1365-2958.2009.06991.x

Breidenstein, E. B. M., Khaira, B. K., Wiegand, I., Overhage, J., and Hancock, R. E. W. (2008). Complex ciprofloxacin resistome revealed by screening a Pseudomonas aeruginosa mutant library for altered susceptibility. Antimicrob. Agents Chemother. 52, 4486-4491. doi: 10.1128/aac.00222-08
DD and EC supervised and coordinated research. BR, LP, ME, $\mathrm{DD}$, and EC wrote the paper.

\section{FUNDING}

This work was granted by a project RAPID (LACTO-TEX) from Direction Générale de l'Armement (DGA, France). This work was also supported by "Investissements d'avenir" program (Méditerranée Infection 10-IAHU-03) of the French Agence Nationale de la Recherche (ANR). BR is a Ph.D. student granted by the "Emplois Jeunes Doctorants" program of Région Provence-Alpes-Côte d'Azur (PACA, France). ME was supported by the MnDrive initiative.

\section{ACKNOWLEDGMENTS}

The authors would like to thank Prof. Bernard Lascola and Lina Barrassi for their advice on the amoeba virulence assay, Dr. Raphael Lami for providing AHL reporter strains and Prof. Sophie Bleves for the E. coli competition assay. The authors also thank Nathan Hoekstra and Sara Maitland for corrections on the manuscript.

\section{SUPPLEMENTARY MATERIAL}

The Supplementary Material for this article can be found online at: https://www.frontiersin.org/articles/10.3389/fmicb. 2020.00762/full\#supplementary-material

Bzdrenga, J., Daudé, D., Rémy, B., Jacquet, P., Plener, L., Elias, M., et al. (2017). Biotechnological applications of quorum quenching enzymes. Chemico-Biol. Interact. 267, 104-115. doi: 10.1016/j.cbi.2016.05.028

Chessa, J.-P., Petrescu, I., Bentahir, M., Van Beeumen, J., and Gerday, C. (2000). Purification, physico-chemical characterization and sequence of a heat labile alkaline metalloprotease isolated from a psychrophilic Pseudomonas species. Biochim. Biophys. Acta (BBA) - Protein Struct. Mol. Enzymol. 1479, 265-274. doi: 10.1016/S0167-4838(00)00018-2

Chevalier, S., Bouffartigues, E., Bodilis, J., Maillot, O., Lesouhaitier, O., Feuilloley, M. G. J., et al. (2017). Structure, function and regulation of Pseudomonas aeruginosa porins. FEMS Microbiol. Rev. 41, 698-722. doi: 10.1093/femsre/ fux020

Chugani, S., Kim, B. S., Phattarasukol, S., Brittnacher, M. J., Choi, S. H., Harwood, C. S., et al. (2012). Strain-dependent diversity in the Pseudomonas aeruginosa quorum-sensing regulon. Proc. Natl. Acad. Sci. U.S.A. 109, E2823-E2831. doi: 10.1073/pnas.1214128109

Collins, P. A., Rodgers, P. B., and Knowles, C. J. (1980). The effect of growth conditions on cyanogenesis by Chromobacterium violaceum. J. General Microbiol. 117:8. doi: 10.1099/00221287-117-1-73

Delgado, C., Florez, L., Lollett, I., Lopez, C., Kangeyan, S., Kumari, H., et al. (2018). Pseudomonas aeruginosa regulated intramembrane proteolysis (RIP): protease $\mathrm{MucP}$ can overcome mutations in the AlgO periplasmic protease to restore alginate production in nonmucoid revertants. J. Bacteriol. 200, e215-e218.

Déziel, E., Lepine, F., Milot, S., He, J., Mindrinos, M. N., Tompkins, R. G., et al. (2004). Analysis of Pseudomonas aeruginosa 4-hydroxy-2alkylquinolines (HAQs) reveals a role for 4-hydroxy-2-heptylquinoline in cellto-cell communication. Proc. Natl. Acad. Sci. U.S.A. 101, 1339-1344. doi: 10. 1073/pnas.0307694100 
Dotsch, A., Becker, T., Pommerenke, C., Magnowska, Z., Jansch, L., and Haussler, S. (2009). Genomewide identification of genetic determinants of antimicrobial drug resistance in Pseudomonas aeruginosa. Antimicrob. Agents Chemother. 53, 2522-2531. doi: 10.1128/aac.00035-09

Drees, S. L., and Fetzner, S. (2015). PqsE of Pseudomonas aeruginosa acts as pathway-specific thioesterase in the biosynthesis of alkylquinolone signaling molecules. Chem. Biol. 22, 611-618. doi: 10.1016/j.chembiol.2015.04.012

Elasri, M., Delorme, S., Lemanceau, P., Stewart, G., Laue, B., Glickmann, E., et al. (2001). Acyl-homoserine lactone production is more common among plantassociated Pseudomonas spp. than among soilborne Pseudomonas spp. Appl. Environ. Microbiol. 67, 1198-1209. doi: 10.1128/AEM.67.3.1198-1209.2001

Elias, M., and Tawfik, D. S. (2012). Divergence and convergence in enzyme evolution: parallel evolution of paraoxonases from quorum-quenching lactonases. J. Biol. Chem. 287, 11-20. doi: 10.1074/jbc.R111.257329

Feinbaum, R. L., Urbach, J. M., Liberati, N. T., Djonovic, S., Adonizio, A., Carvunis, A.-R., et al. (2012). Genome-Wide Identification of Pseudomonas aeruginosa virulence-related genes using a caenorhabditis elegans infection model. PLoS Pathog. 8:e1002813. doi: 10.1371/journal.ppat.1002813

Feltner, J. B., Wolter, D. J., Pope, C. E., Groleau, M.-C., Smalley, N. E., Greenberg, E. P., et al. (2016). LasR variant cystic fibrosis isolates reveal an adaptable quorum-sensing hierarchy in Pseudomonas aeruginosa. mBio 7:e1513. doi: 10. 1128/mBio.01513-16

Fenner, L., Richet, H., Raoult, D., Papazian, L., Martin, C., and La Scola, B. (2006). Are clinical isolates of Pseudomonas aeruginosa more virulent than hospital environmental isolates in amebal co-culture test? Crit. Care Med. 34, 823-828. doi: 10.1097/01.CCM.0000201878.51343.F1

Fraley, C. D., Rashid, M. H., Lee, S. S. K., Gottschalk, R., Harrison, J., Wood, P. J., et al. (2007). A polyphosphate kinase 1 (ppk1) mutant of Pseudomonas aeruginosa exhibits multiple ultrastructural and functional defects. Proc. Natl. Acad. Sci. U.S.A. 104, 3526-3531. doi: 10.1073/pnas.0609733104

Fuqua, C., and Greenberg, E. P. (2002). Listening in on bacteria: acyl-homoserine lactone signalling. Nat. Rev. Mol. Cell Biol. 3, 685-695. doi: 10.1038/nrm907

Gaviard, C., Broutin, I., Cosette, P., Dé, E., Jouenne, T., and Hardouin, J. (2018). Lysine Succinylation and Acetylation in Pseudomonas aeruginosa. J. Proteome Res. 17, 2449-2459. doi: 10.1021/acs.jproteome.8b00210

Grandclément, C., Tannières, M., Moréra, S., Dessaux, Y., and Faure, D. (2016). Quorum quenching: role in nature and applied developments. FEMS Microbiol. Rev. 40, 86-116. doi: 10.1093/femsre/fuv038

Guendouze, A., Plener, L., Bzdrenga, J., Jacquet, P., Rémy, B., Elias, M., et al. (2017). Effect of quorum quenching lactonase in clinical isolates of Pseudomonas aeruginosa and comparison with quorum sensing inhibitors. Front. Microbiol. 8:227. doi: $10.3389 /$ fmicb.2017.00227

Harrison, J. J., Stremick, C. A., Turner, R. J., Allan, N. D., Olson, M. E., and Ceri, H. (2010). Microtiter susceptibility testing of microbes growing on peg lids: a miniaturized biofilm model for high-throughput screening. Nat. Protoc. 5, 1236-1254. doi: 10.1038/nprot.2010.71

Häussler, S., and Becker, T. (2008). The Pseudomonas quinolone signal (PQS) balances life and death in Pseudomonas aeruginosa populations. PLoS Pathogens 4:e1000166. doi: 10.1371/journal.ppat.1000166

Hay, I. D., Wang, Y., Moradali, M. F., Rehman, Z. U., and Rehm, B. H. A. (2014). Genetics and regulation of bacterial alginate production: regulation of bacterial alginate. Environ. Microbiol. 16, 2997-3011. doi: 10.1111/1462-2920.12389

Hazan, R., Que, Y. A., Maura, D., Strobel, B., Majcherczyk, P. A., Hopper, L. R., et al. (2016). Auto poisoning of the respiratory chain by a quorum-sensingregulated molecule favors biofilm formation and antibiotic tolerance. Curr. Biol. 26, 195-206. doi: 10.1016/j.cub.2015.11.056

Hentzer, M., Wu, H., Andersen, J. B., Riedel, K., Rasmussen, T. B., Bagge, N., et al. (2003). Attenuation of Pseudomonas aeruginosa virulence by quorum sensing inhibitors. EMBO J. 22, 3803-3815. doi: 10.1093/emboj/cdg366

Hiblot, J., Gotthard, G., Elias, M., and Chabriere, E. (2013). Differential active site loop conformations mediate promiscuous activities in the lactonase SsoPox. PLOS ONE 8:e75272. doi: 10.1371/journal.pone.0075272

Hinz, A., Lee, S., Jacoby, K., and Manoil, C. (2011). Membrane proteases and aminoglycoside antibiotic resistance. J. Bacteriol. 193, 4790-4797. doi: 10.1128/ JB.05133-11

Hoffman, L. R., D’Argenio, D. A., MacCoss, M. J., Zhang, Z., Jones, R. A., and Miller, S. I. (2005). Aminoglycoside antibiotics induce bacterial biofilm formation. Nature 436, 1171-1175. doi: 10.1038/nature03912
Hraiech, S., Hiblot, J., Lafleur, J., Lepidi, H., Papazian, L., Rolain, J.-M., et al. (2014). Inhaled lactonase reduces Pseudomonas aeruginosa quorum sensing and mortality in rat pneumonia. PLOS ONE 9:e107125. doi: 10.1371/journal.pone. 0107125

Jiang, F., Waterfield, N. R., Yang, J., Yang, G., and Jin, Q. (2014). A Pseudomonas aeruginosa Type VI secretion phospholipase $\mathrm{D}$ effector targets both prokaryotic and eukaryotic cells. Cell Host \& Microbe 15, 600-610. doi: 10.1016/j.chom. 2014.04.010

Kim, H.-Y., Schlictman, D., Shankar, S., Xie, Z., Chakrabarty, A. M., and Kornberg, A. (1998). Alginate, inorganic polyphosphate, GTP and ppGpp synthesis coregulated in Pseudomonas aeruginosa: implications for stationary phase survival and synthesis of RNA/DNA precursors. Mol. Microbiol. 27, 717-725. doi: 10. 1046/j.1365-2958.1998.00702.x

Kostylev, M., Kim, D. Y., Smalley, N. E., Salukhe, I., Greenberg, E. P., and Dandekar, A. A. (2019). Evolution of the Pseudomonas aeruginosa quorumsensing hierarchy. Proc. Natl. Acad. Sci. U.S.A. 116, 7027-7032. doi: 10.1073/ pnas. 1819796116

Latifi, A., Foglino, M., Tanaka, K., Williams, P., and Lazdunski, A. (1996). A hierarchical quorum-sensing cascade in Pseudomonas aeruginosa links the transcriptional activators LasR and RhlR (VsmR) to expression of the stationary-phase sigma factor RpoS. Mol. Microbiol. 21, 1137-1146. doi: 10. 1046/j.1365-2958.1996.00063.x

Lee, J., and Zhang, L. (2015). The hierarchy quorum sensing network in Pseudomonas aeruginosa. Protein \& Cell 6, 26-41. doi: 10.1007/s13238-0140100- $\mathrm{x}$

Lee, Y., Song, S., Sheng, L., Zhu, L., Kim, J.-S., and Wood, T. K. (2018). Substrate binding protein DppA1 of $\mathrm{ABC}$ transporter DppBCDF increases biofilm formation in Pseudomonas aeruginosa by inhibiting Pf5 prophage lysis. Front. Microbiol. 9:30. doi: 10.3389/fmicb.2018.00030

Lesic, B., Starkey, M., He, J., Hazan, R., and Rahme, L. G. (2009). Quorum sensing differentially regulates Pseudomonas aeruginosa type VI secretion locus I and homologous loci II and III, which are required for pathogenesis. Microbiology 155, 2845-2855. doi: 10.1099/mic.0.029082-0

Lister, P. D., Wolter, D. J., and Hanson, N. D. (2009). Antibacterialresistant Pseudomonas aeruginosa: clinical impact and complex regulation of chromosomally encoded resistance mechanisms. Clin. Microbiol. Rev. 22, 582-610. doi: 10.1128/CMR.00040-09

Mahan, K., Martinmaki, R., Larus, I., Sikdar, R., Dunitz, J., and Elias, M. (2020). Effects of signal disruption depends on the substrate preference of the lactonase. Front. Microbiol. 10:3003. doi: 10.3389/fmicb.2019.03003

Marquart, M. E., Caballero, A. R., Chomnawang, M., Thibodeaux, B. A., Twining, S. S., and O'Callaghan, R. J. (2005). Identification of a novel secreted protease from Pseudomonas aeruginosa that causes corneal erosions. Invest. Opthalmol. Vis. Sci. 46:3761. doi: 10.1167/iovs.04-1483

Matz, C., Moreno, A. M., Alhede, M., Manefield, M., Hauser, A. R., Givskov, M., et al. (2008). Pseudomonas aeruginosa uses type III secretion system to kill biofilm-associated amoebae. ISME J. 2, 843-852. doi: 10.1038/ismej.2008.47

Maura, D., Hazan, R., Kitao, T., Ballok, A. E., and Rahme, L. G. (2016). Evidence for direct control of virulence and defense gene circuits by the Pseudomonas aeruginosa quorum sensing regulator, MvfR. Sci. Rep. 6:34083. doi: 10.1038/ srep34083

Maura, D., and Rahme, L. G. (2017). Pharmacological inhibition of the Pseudomonas aeruginosa MvfR quorum-sensing system interferes with biofilm formation and potentiates antibiotic-mediated biofilm disruption. Antimicrob. Agents Chemother. 61, e1362-e1317. doi: 10.1128/AAC.01362-17

McClean, K. H., Chhabra, S. R., Camara, M., Daykin, M., Swift, S., Bycroft, B. W., et al. (1997). Quorum sensing and Chromobacterium violaceum:exploitation of violacein production and inhibition for the detection of $\mathrm{N}$-acylhomoserine lactones. Microbiology 143, 3703-3711. doi: 10.1099/00221287-143-123703

Merone, L., Mandrich, L., Rossi, M., and Manco, G. (2005). A thermostable phosphotriesterase from the archaeon Sulfolobus solfataricus: cloning, overexpression and properties. Extremophiles 9, 297-305. doi: 10.1007/s00792005-0445-4

Miklavič, Š, Kogovšek, P., Hodnik, V., Korošec, J., Kladnik, A., Anderluh, G., et al. (2015). The Pseudomonas aeruginosa RhlR-controlled aegerolysin RahU is a low-affinity rhamnolipid-binding protein. FEMS Microbiol. Lett. 362:fnv069. doi: 10.1093/femsle/fnv069 
Mion, S., Rémy, B., Plener, L., Brégeon, F., Chabrière, E., and Daudé, D. (2019). Quorum quenching lactonase strengthens bacteriophage and antibiotic arsenal against Pseudomonas aeruginosa clinical isolates. Front. Microbiol. 10:2049. doi: 10.3389/fmicb.2019.02049

Nalca, Y., Jänsch, L., Bredenbruch, F., Geffers, R., Buer, J., and Häussler, S. (2006). Quorum-sensing antagonistic activities of azithromycin in Pseudomonas aeruginosa PAO1: a global approach. Antimicrob Agents Chemother. 50, 16801688. doi: 10.1128/AAC.50.5.1680-1688.2006

O’Loughlin, C. T., Miller, L. C., Siryaporn, A., Drescher, K., Semmelhack, M. F., and Bassler, B. L. (2013). A quorum-sensing inhibitor blocks Pseudomonas aeruginosa virulence and biofilm formation. Proc. Natl. Acad. Sci. U.S.A. 110, 17981-17986. doi: 10.1073/pnas.1316981110

Papenfort, K., and Bassler, B. L. (2016). Quorum sensing signal-response systems in Gram-negative bacteria. Nat. Rev. Microbiol. 14, 576-588. doi: 10.1038/ nrmicro.2016.89

Perez-Riverol, Y., Csordas, A., Bai, J., Bernal-Llinares, M., Hewapathirana, S., Kundu, D. J., et al. (2019). The PRIDE database and related tools and resources in 2019: improving support for quantification data. Nucleic Acids Res. 47, D442-D450. doi: 10.1093/nar/gky1106

Price-Whelan, A., Dietrich, L. E. P., and Newman, D. K. (2007). Pyocyanin alters redox homeostasis and carbon flux through central metabolic pathways in Pseudomonas aeruginosa PA14. J. Bacteriol. 189, 6372-6381. doi: 10.1128/JB. 00505-07

Pukatzki, S., Kessin, R. H., and Mekalanos, J. J. (2002). The human pathogen Pseudomonas aeruginosa utilizes conserved virulence pathways to infect the social amoeba Dictyostelium discoideum. Proc. Natl. Acad. Sci. U.S.A. 99, 3159-3164. doi: 10.1073/pnas.052704399

Qiu, D., Eisinger, V. M., Rowen, D. W., and Yu, H. D. (2007). Regulated proteolysis controls mucoid conversion in Pseudomonas aeruginosa. Proc. Natl. Acad. Sci. U.S.A. 104, 8107-8112. doi: 10.1073/pnas.0702660104

Rampioni, G., Falcone, M., Heeb, S., Frangipani, E., Fletcher, M. P., Dubern, J.-F., et al. (2016). Unravelling the genome-wide contributions of specific 2-Alkyl4-quinolones and PqsE to quorum sensing in Pseudomonas aeruginosa. PLoS Pathog. 12:e1006029. doi: 10.1371/journal.ppat.1006029

Reichhardt, C., and Wong, C. (2018). CdrA interactions within the Pseudomonas aeruginosa biofilm matrix safeguard it from proteolysis and promote cellular packing. mBio 9:12.

Rémy, B., Mion, S., Plener, L., Elias, M., Chabrière, E., and Daudé, D. (2018). Interference in bacterial quorum sensing: a biopharmaceutical perspective. Front. Pharmacol. 9:203. doi: 10.3389/fphar.2018.00203

Sakhtah, H., Koyama, L., Zhang, Y., Morales, D. K., Fields, B. L., Price-Whelan, A., et al. (2016). The Pseudomonas aeruginosa efflux pump MexGHI-OpmD transports a natural phenazine that controls gene expression and biofilm development. Proc. Natl. Acad. Sci. U.S.A. 113, E3538-E3547. doi: 10.1073/pnas. 1600424113

Sana, T. G., Soscia, C., Tonglet, C. M., Garvis, S., and Bleves, S. (2013). Divergent control of two type VI secretion systems by RpoN in Pseudomonas aeruginosa. PLoS ONE 8:e76030. doi: 10.1371/journal.pone.0076030

Sanz-García, F., Alvarez-Ortega, C., Olivares-Pacheco, J., Blanco, P., Martínez, J. L., and Hernando-Amado, S. (2019). Analysis of the Pseudomonas aeruginosa aminoglycoside differential resistomes allows defining genes simultaneously involved in intrinsic antibiotic resistance and virulence. Antimicrob. Agents Chemother. 63:e00185-19. doi: 10.1128/AAC.00185-19

Schmittgen, T. D., and Livak, K. J. (2008). Analyzing real-time PCR data by the comparative CT method. Nat. Protoc. 3, 1101-1108. doi: 10.1038/nprot.2008.73

Seo, J., and Darwin, A. J. (2013). The Pseudomonas aeruginosa periplasmic protease CtpA can affect systems that impact its ability to mount both acute and chronic infections. Infect. Immun. 81, 4561-4570. doi: 10.1128/IAI.01035-13

Sethupathy, S., Prasath, K. G., Ananthi, S., Mahalingam, S., Balan, S. Y., and Pandian, S. K. (2016). Proteomic analysis reveals modulation of iron homeostasis and oxidative stress response in Pseudomonas aeruginosa PAO1 by curcumin inhibiting quorum sensing regulated virulence factors and biofilm production. J. Proteom. 145, 112-126. doi: 10.1016/j.jprot.2016.04.019
Sievert, D. M., Ricks, P., Edwards, J. R., Schneider, A., Patel, J., Srinivasan, A., et al. (2013). Antimicrobial-resistant pathogens associated with healthcareassociated infections summary of data reported to the national healthcare safety network at the centers for disease control and prevention, 2009-2010. Infect. Control Hosp. Epidemiol. 34, 1-14. doi: 10.1086/668770

Smith, K. M., Bu, Y., and Suga, H. (2003). Induction and inhibition of Pseudomonas aeruginosa quorum sensing by synthetic autoinducer analogs. Chem. Biol. 10, 81-89. doi: 10.1016/S1074-5521(03)00002-4

Somprasong, N., Jittawuttipoka, T., Duang-nkern, J., Romsang, A., Chaiyen, P., Schweizer, H. P., et al. (2012). Pseudomonas aeruginosa thiol peroxidase protects against hydrogen peroxide toxicity and displays atypical patterns of gene regulation. J. Bacteriol. 194, 3904-3912. doi: 10.1128/JB.00347-12

Steidle, A., Sigl, K., Schuhegger, R., Ihring, A., Schmid, M., Gantner, S., et al. (2001). Visualization of $\mathrm{N}$-acylhomoserine lactone-mediated cell-cell communication between bacteria colonizing the tomato rhizosphere. Appl. Environ. Microbiol. 67, 5761-5770. doi: 10.1128/AEM.67.12.5761-5770.2001

Studier, F. W. (2005). Protein production by auto-induction in high-density shaking cultures. Protein Expression Purif. 41, 207-234. doi: 10.1016/j.pep.2005. 01.016

Sundin, G. W., Shankar, S., Chugani, S. A., Chopade, B. A., Kavanaugh-Black, A., and Chakrabarty, A. M. (1996). Nucleoside diphosphate kinase from Pseudomonas aeruginosa: characterization of the gene and its role in cellular growth and exopolysaccharide alginate synthesis. Mol. Microbiol. 20, 965-979. doi: 10.1111/j.1365-2958.1996.tb02538.x

Verstraeten, N., Knapen, W. J., Kint, C. I., Liebens, V., Van den Bergh, B., Dewachter, L., et al. (2015). Obg and membrane depolarization are part of a microbial bet-hedging strategy that leads to antibiotic tolerance. Mol. Cell 59, 9-21. doi: 10.1016/j.molcel.2015.05.011

Weiner, L. M., Webb, A. K., Limbago, B., Dudeck, M. A., Patel, J., Kallen, A. J., et al. (2016). Antimicrobial-resistant pathogens associated with healthcareassociated infections: summary of data reported to the national healthcare safety network at the centers for disease control and prevention, 2011-2014. Infect. Control Hosp. Epidemiol. 37, 1288-1301. doi: 10.1017/ice.2016.174

Welsh, M. A., and Blackwell, H. E. (2016). Chemical genetics reveals environmentspecific roles for quorum sensing circuits in Pseudomonas aeruginosa. Cell Chem. Biol. 23, 361-369. doi: 10.1016/j.chembiol.2016.01.006

Welsh, M. A., Eibergen, N. R., Moore, J. D., and Blackwell, H. E. (2015). Small molecule disruption of quorum sensing cross-regulation in Pseudomonas aeruginosa causes major and unexpected alterations to virulence phenotypes. J. Am. Chem. Soc. 137, 1510-1519. doi: 10.1021/ja5110798

Winsor, G. L., Griffiths, E. J., Lo, R., Dhillon, B. K., Shay, J. A., and Brinkman, F. S. L. (2016). Enhanced annotations and features for comparing thousands of Pseudomonas genomes in the Pseudomonas genome database. Nucleic Acids Res. 44, D646-D653. doi: 10.1093/nar/gkv1227

Wolloscheck, D., Krishnamoorthy, G., Nguyen, J., and Zgurskaya, H. I. (2018). Kinetic control of quorum sensing in Pseudomonas aeruginosa by multidrug efflux pumps. ACS Infect. Dis. 4, 185-195. doi: 10.1021/acsinfecdis.7b00160

Conflict of Interest: ME and EC have a patent WO2014167140 A1 licensed to Gene\&GreenTK. LP, DD, BR, ME, and EC report personal fees from Gene\&GreenTK during the conduct of the study.

The remaining authors declare that the research was conducted in the absence of any commercial or financial relationships that could be construed as a potential conflict of interest.

Copyright (C) 2020 Rémy, Plener, Decloquement, Armstrong, Elias, Daudé and Chabrière. This is an open-access article distributed under the terms of the Creative Commons Attribution License (CC BY). The use, distribution or reproduction in other forums is permitted, provided the original author(s) and the copyright owner(s) are credited and that the original publication in this journal is cited, in accordance with accepted academic practice. No use, distribution or reproduction is permitted which does not comply with these terms. 